\title{
Stem cell transplantation in neurological diseases: improving effectiveness in animal models
}

\section{Raffaella Adami, Giuseppe Scesa and Daniele Bottai*}

Department of Health Science, Faculty of Medicine, University of Milan, Milan, Italy

\section{Edited by:}

Cedric Viero, Saarland University

Medical Faculty, Germany

Reviewed by:

Stefan Hauser, Deutsches Zentrum

für Neurodegenerative

Erkrankungen, Germany

Loic P. Deleyrolle, University of

Florida, USA

Dromard Berthézène Cécile,

StromaLab UMR UPS/CNRS 5273,

EFS, Inserm U1031, France

\section{${ }^{*}$ Correspondence:}

Daniele Bottai, Department of

Health Science, Faculty of Medicine,

University of Milan, Via A. di

Rudini 8, Milan, 20142, Italy

e-mail: daniele.bottai@unimi.it
Neurological diseases afflict a growing proportion of the human population. There are two reasons for this: first, the average age of the population (especially in the industrialized world) is increasing, and second, the diagnostic tools to detect these pathologies are now more sophisticated and can be used on a higher percentage of the population. In many cases, neurological disease has a pharmacological treatment which, as in the case of Alzheimer's disease, Parkinson's disease, Epilepsy, and Multiple Sclerosis can reduce the symptoms and slow down the course of the disease but cannot reverse its effects or heal the patient. In the last two decades the transplantation approach, by means of stem cells of different origin, has been suggested for the treatment of neurological diseases. The choice of slightly different animal models and the differences in methods of stem cell preparation make it difficult to compare the results of transplantation experiments. Moreover, the translation of these results into clinical trials with human subjects is difficult and has so far met with little success. This review seeks to discuss the reasons for these difficulties by considering the differences between human and animal cells (including isolation, handling and transplantation) and between the human disease model and the animal disease model.

Keywords: stem cells, animal models, amyotrophic lateral sclerosis, Parkinson's disease, spinal muscular atrophy, spinal cord injury, epilepsy, stroke

\section{INTRODUCTION}

\section{NEUROLOGICAL DISEASES}

There are three types of neurological disorders. Firstly there are the disorders which involve a loss of cells in defined subsets of the brain, such as Parkinson's disease (PD), Alzheimer's disease (AD), and Multiple Sclerosis (MS), and Spinal Muscular Atrophy (SMA). Secondly there are diseases where cells are lost following acute damage, such as Stroke, Brain Trauma or Spinal Cord Injury (SCI). Thirdly we have the disorders which involve the impairment of cell function without cell death, like Epilepsy (Leppik et al., 2006) (Table 1).

A knowledge of the characteristics of the diseases is crucial to finding the appropriate transplantation strategy. Diseases which present, at the time of diagnosis, an extended impairment require an intervention aimed at the replacement of the damaged or dead cells; if the damage is limited, on the other hand, a trophic or anti-inflammatory role for the transplanted cells can be beneficial.

\section{Parkinson's disease}

When the British doctor James Parkinson, in 1817, described the disorder as "shaking palsy" he was almost 7000 years late. Indeed, the first documented description of this disease is from 5000 BC: in an ancient Indian civilization it was given the name Kampavata. The document which described it recommended treatment using the seeds of a plant containing therapeutic levels of what is today known as levodopa (Manyam and Sanchez-Ramos, 1999).
Parkinson's disease is the second most common neurodegenerative disorder ( $\mathrm{AD}$ is the most common) and the most common movement disorder. It is characterized by progressive loss of muscle control, which leads to trembling of the head and limbs while at rest, impaired balance, stiffness, and slowness (Jankovic, 2008). Unfortunately, by the time the symptoms are evident, the neurological damage is already severe, with a massive loss of dopaminergic neurons in the substantia nigra (Double, 2012).

For over 30 years, the most widely used treatment of PD has been levodopa (L-DOPA) which is converted into dopamine in the dopaminergic neurons by dopa decarboxylase. Since motor symptoms are caused by a deficiency of dopamine in the substantia nigra, the administration of L-DOPA pro tempore diminishes the motor symptoms.

Sporadic PD has unknown causes; some hypotheses about the role of environmental toxins were widely supported during much of the 20th century. However, views on the pathology of PD have changed for two reasons, as follow. Firstly, there are no persuasive data to indicate that any specific toxin is a cause of sporadic $\mathrm{PD}$, and chronic environmental exposure to 1-methyl-4-phenyl1,2,3,6-tetrahydropyridine (MPTP) or rotenone is unlikely to cause PD for chemical reasons (Brown et al., 2006). Secondly, recent work shows that mutation of genes is associated with only a very small proportion of cases (Antony et al., 2013). Only $10 \%$ of all PD cases are caused by genetic mutations, and animal models of these mutations ( $\alpha$-synuclein and LRRK2, autosomal dominant PD) and (PINK1/Parkin and DJ-1, autosomal recessive PD) are important since they represent a possible 
Table 1 | Pharmacological treatments of the common neurological diseases.

\begin{tabular}{ll}
\hline Pathology & Pharmacological treatment \\
\hline Parkinson's disease & Current Parkinson's disease (PD) therapy is essentially symptomatic, and L-Dopa \\
& (LD), is the treatment of choice in more advanced stages of the disease. However, \\
& motor complications often develop after long-term treatment, and at this point \\
& physicians usually prescribe adjuvant therapy with other classes of antiparkinsonian \\
& drugs, including dopamine (DA) agonists, anticholinergic, catechol-O-methyl \\
& transferase (COMT) or monoamine oxidase (MAO)-B inhibitors
\end{tabular}

\begin{tabular}{|c|c|c|}
\hline Alzheimer's disease & Anticholinergic, inhibitory of NMDA receptor drugs and neuroprotective drugs & van de Glind et al., 2013 \\
\hline Multiple sclerosis & Interferon(IFN)- $\beta$ and disease modifying drugs & $\begin{array}{l}\text { Marta and Giovannoni, 2012; } \\
\text { Fernandez et al., } 2013\end{array}$ \\
\hline Amyotrophic lateral sclerosis & Riluzole & Morren and Galvez-Jimenez, 2012 \\
\hline Spinal muscular atrophy & No US Food and Drug Administration (FDA) approved treatment for SMA & Cherry and Androphy, 2012 \\
\hline Spinal cord injury & $\begin{array}{l}\text { Despite numerous studies reporting some measures of efficacy in the animal } \\
\text { literature, there are currently no effective therapies for the treatment of traumatic } \\
\text { spinal cord injuries (SCI) in humans. Methylprednisolone (MP) for instance is not } \\
\text { FDA approved for this application }\end{array}$ & $\begin{array}{l}\text { Rabchevsky et al., 2011; Hurlbert } \\
\text { et al., } 2013\end{array}$ \\
\hline
\end{tabular}

\begin{tabular}{ll}
\hline Epilepsy & $\mathrm{Ca}^{2+}$ channel blockers, GABA uptake inhibitors, $\mathrm{Na}^{+}$channel modulators, GABAA \\
receptor allosteric modulators, NMDA receptor antagonists
\end{tabular}

Stroke Mostly anticoagulant and thrombolysis agents

Plosker, 2014

therapeutic target (Dauer and Przedborski, 2003). Most likely the concomitant differences in the genome (for instance the presence of polymorphisms), the patient's age and the presence of environmental factors can all contribute to an increased risk of PD from an epidemiological point of view (Gao and Hong, 2011; Antony et al., 2013). An example of the combination of a variation of the genome and an environmental factor is that an Aldehyde dehydrogenase variation enhances the effect of pesticides associated with Parkinson disease (Fitzmaurice et al., 2014).

\section{Alzheimer's disease}

More than 35 million people worldwide are affected by $\mathrm{AD}$, a progressive neurodegenerative illness that slowly deprives individuals of their memories and other cognitive functions (Ferri et al., 2005; Sosa-Ortiz et al., 2012). The prevalence of dementia increases from $0.9 \%$ in 65 - to 69 -year-olds to over $30 \%$ in people aged 85 years and older (Ferri et al., 2005).

There are many risk factors for dementia, three of which are constant and unchangeable: a family history of dementia, older age, and apolipoprotein E genotype e4 allele. Of the other risk factors for dementia some depend on education and occupational achievements; while others are related to cardiovascular risk factors (smoking, hypertension, diabetes, and obesity) and lifestyle and psychosocial factors (depression, physical activity and alcohol consumption) (Sosa-Ortiz et al., 2012) and can be changed in some ways by the patient.

One of the most important problem is that patients with dementia cannot be healed: the process of cognitive decline can merely be delayed. In numerous countries, cholinesterase inhibitors and memantine are registered for the treatment of cognitive impairment in $\mathrm{AD}$ (Cummings et al., 2013).

\section{Multiple sclerosis}

Multiple Sclerosis is an autoimmune disease which targets the myelinated central nervous system (CNS) tracts. It is the most common chronic inflammatory demyelinating disorder of the CNS, and the leading cause of non-traumatic neurological disability in young adults, affecting $0.1 \%$ of the general population in Western countries (Noseworthy et al., 2000). There are many risk factors that could be considered to be responsible for the pathology, among which are environmental risk factors such as infections like measles and Epstein-Barr virus, climate and solar conditions, living conditions and trace elements in the diet (Rosati, 2001).

The inflammation damages the blood-brain barrier and induces the destruction of myelin and the consequent axon damage, gliosis and the formation of sclerotic plaques (Nylander and Hafler, 2012). Continuing lesion formation in MS often leads to physical disability and to cognitive decline. The course of the disease varies between patients, for example more than $60 \%$ lose ambulatory capability within 20 years of onset while others are not affected.

Almost $80 \%$ of patients will initially present unpredictable attacks (relapses), of variable duration, in which new symptoms appear or existing symptoms become more severe. At the end of the attack, there is a partial or complete recovery. However, symptoms may become more severe and the recovery of function less complete after each attack (Luessi et al., 2012). 
No curative therapy is currently available; therapies are mainly directed to preserving CNS cells, inducing remyelination, and modulating $T$ cells. Interferon (IFN)- $\beta$ was the first agent to show clinical efficacy in the most common form of MS, relapsingremitting MS. IFN- $\beta$ treatment reduces relapse rates by about $30 \%$, decreases the formation of inflammatory lesions in the CNS, elongates remission periods, and possibly slows down the progression of disability (Schwid and Panitch, 2007). In determining the risk of developing MS, environmental and hereditary factors need to be regarded as acting in tandem; on this, the lessons learned in connection with PD will assist our understanding of the mechanisms of the pathology for a number of patients (Koch et al., 2013; Munoz-Culla et al., 2013).

\section{Amyotrophic lateral sclerosis}

Charcot described ALS in 1874. It is the most common form of the neurodegenerative disorders collectively referred to as motor neuron disease, and has a higher incidence in women. The sixth decade is the most common age at which the disease has its onset. $5-10 \%$ of cases are familial and the remainder are regarded as sporadic (Rowland and Shneider, 2001). The familial forms involve the mutation of many genes: superoxide dismutase 1 (SOD1) (Rosen et al., 1993), fused in sarcoma (FUS) (Kwiatkowski et al., 2009; Vance et al., 2009), TAR DNA-binding protein 43 (TDP43) (Kabashi et al., 2008), or chromosome 9 open reading frame 72 (C9orf72) genes (Dejesus-Hernandez et al., 2011; Renton et al., 2011). However, a most important recent discovery was that of intronic hexanucleotide repeat expansions in chromosome 9 open reading frame 72 (C9orf72) as a common cause of ALS, frontotemporal lobar degeneration (FTLD) and ALS with concomitant FTLD. The high frequency of C9orf72 mutations in patients lacking a family history of ALS further blurred the distinction between the sporadic and the familial forms of ALS and FTLD (Dejesus-Hernandez et al., 2011; Renton et al., 2011).

Clinical studies had already suggested that ALS and FTLD represent two extremes of a spectrum of neurodegenerative disorders, which co-occur in up to $15 \%$ of patients (Lomen-Hoerth et al., 2003). An association between dementia and ALS was noticed as early as the late 19th century. After this initial discovery, many other authors reported similar data (Neary et al., 2000).

The strongest evidence for considering ALS and FTLD as one disease, however, comes from the discovery that C9orf72 mutations are a prevalent cause of ALS, ALS-FTLD, and FTLD (Kwiatkowski et al., 2009; Vance et al., 2009) and are most likely responsible for approximately $40 \%$ of ALS and for approximately $25 \%$ of familial FTLD (Van Blitterswijk et al., 2012).

ALS is a heterogeneous disorder at almost all levels: clinical, genetic and mechanistic. For instance the ranges of age of onset and rate of progression of the disease are wide; even when the same type of mutation is present, age at onset and survival rates vary substantially (Regal et al., 2006). This heterogeneity remains unexplored and little understood (Van Damme et al., 2013).

Drugs have little effect on disease progression, so other, multidisciplinary, strategies are required. For instance artificial ventilation and feeding tubes are the main care options. Furthermore, since cognitive functions and emotional ability seem to be affected by this disease (Abrahams et al., 1995) psychological intervention is desirable.

The only drug approved by the U.S. Food and Drug Administration for the treatment of ALS is riluzole, a glutamate antagonist. In two therapeutic trials, riluzole prolonged survival by 3-6 months (Bensimon et al., 1994; Lacomblez et al., 1996).

\section{Stroke}

Stroke is the abrupt loss of brain function due to alteration in the blood supply to the brain. It is recognized as the second leading cause of death worldwide; its incidence depends on age and race (Grossman and Broderick, 2013).

Small and large artery occlusions are the main factors responsible for the pathology, with the occlusion of intra- and extracranial large vessels seeming to involve endothelial injury and platelet aggregation. When smaller vessels are occluded there is a similarity with arteriosclerosis due to common vascular risk factors of diabetes, hypertension, and hypercholesterolemia. The canonical therapeutical approach is mostly directed to the reduction of the thrombus and the prevention of clot formation (Grossman and Broderick, 2013; Plosker, 2014). Little is known and little action is taken of a neuroprotective or neuromodulatory nature on patients affected by stroke. The main target is the recovery of language by means of dopamine precursors, or agonists, or cholinergic neuromodulation (Breitenstein et al., 2006).

\section{Spinal muscular atrophy}

Spinal muscular atrophy is one of the most devastating childhood diseases since it affects babies from birth onwards (it can occasionally be detected during gestation), and in its more severe form-type 1 or Werdnig-Hoffmann disease, in which patients cannot sit and some of them cannot control the position of their head-life expectancy does not exceed 2 years. Type 2 SMA is an intermediate form whose onset is between 7 and 18 months of age; patients can sit but never stand and they can survive to adulthood. Type 3 SMA (Kugelberg and Welander) has its onset after the 30th month of life. The severity of the disease is classified by the degree of muscle weakness (before or after 3 years); the patient can walk but in some more severe forms they stop walking in adulthood. Finally type 4 SMA has its onset between the 10 and the 30th years of life; length of life is as with type 3 and patients can stand and walk and-if well trained-continue doing so all their life (Mercuri et al., 2012; Bottai and Adami, 2013).

SMA is a genetic disease caused by a loss of function mutation of a telomeric gene called Survival Motor Neuron 1 (SMN1) (Burglen et al., 1995, 1996). The pathology is very variable and depends on the number of copies of another centromeric gene, the Survival Motor Neuron 2 (SMN2), which can transcribe for the same protein although with a lower rate of expression (Campbell et al., 1997; Bottai and Adami, 2013). So far no pharmacological treatment has been shown to be effective, although the various clinical trials performed even recently need to be revisited, as there is a great variability of response to pharmacological treatment between different patients (Garbes et al., 2013). 


\section{Spinal cord injury}

Mechanical damage to the spinal cord results in dramatic change in the capabilities of the CNS. In SCI the force applied to the bones (due to work, or car, bike or sports accident) can deform and break the bone itself and can damage the nervous tissue.

This is called primary damage and depends on the amount of energy transferred to the nervous tissue. In this pathology there is, however, secondary damage due to the response of the immune system of the patient, which tries to repair the damage but actually causes more impairment. Indeed, many substances produced by leukocytes are neurotoxic and have been implicated in the onset and progression of CNS autoimmune and neurodegenerative diseases (Feuerstein et al., 1998). The secondary damage in many cases is even more severe than the primary damage, and is often responsible for the chronic effects that the patient will face in later life.

Due to the wide range of degree and type of damage in human patients it is difficult to find a single strategy for the treatment of SCI: in most cases the current therapeutic algorithm includes early surgery consisting of decompression of the spinal cord and stabilization of the spine in indicated cases. As soon as the patient's injuries (often multiple) become stable, the patient is transferred to a specialized rehabilitation center. Nonetheless, there is no treatment available today that can lead to the repair of the damaged spinal cord tissue. The current standard therapy consists of the administration of methylprednisolone sodium succinate (MPSS) to reduce SCI damage by decreasing lipid peroxidation and free radical production, and preventing edema taking place during ischemia and re-perfusion.

\section{Epilepsy}

Epilepsy, also known as seizure disorder, is a pathological condition that brings about seizures and affects a range of mental and physical functions (Mattson, 2003). Seizures are caused by a malfunction of the electrical system of the brain, with an uncontrolled discharge that makes the brain cells keep firing. This results in a flux of energy through the brain, causing muscle contractions and unconsciousness. When a person has at least two seizures without another known cause, they are considered to have epilepsy.

There are various kinds of seizures, which the experts divide into generalized seizures (absence, atonic, tonic-clonic and myoclonic), partial (simple and complex) and status epilepticus (Mattson, 2003; Beydoun and D'souza, 2012).

In many cases-about 70\%-no cause can be found. In other cases, the epilepsy can be due to head injuries or lack of oxygen during parturition, which may alter the delicate electrical system in the brain, genetic conditions (such as tuberous sclerosis), lead poisoning, brain tumors, problems in the development of the brain before birth and infections like meningitis or encephalitis.

Anti-epileptic drugs vary in structure and function, and in many cases their clinical activity is not understood. The antiepileptics have three main intended effects: membrane stabilization, reduction of neurotransmitter release and increase of GABA-mediated inhibition (Leppik et al., 2006; Howard et al., 2011).

\section{TRANSPLANTATION METHODS}

Transplanting cells involves different sets of questions that need to be taken into account in preclinical and clinical trials.

\section{Disease}

The first one is whether the pathology induces the death of brain cells or rather initiates a change in the interactions between cells. The second concerns the possibility - which exists only when it is known that the blood brain barrier (BBB) is open-of systemic transplantation. A further one, with regard to the disease itself, is whether the pathology induces an inflammatory response, in which case the role of the transplanted cells should be not only substitutional but also anti-inflammatory. These are all relevant concerns needing to be taken into account in the case of almost all the cells that have been used in clinical trials.

\section{Stem cell use}

Given the foregoing, the choice of the cells to be transplanted can be very wide.

Many different types of stem cells have a potential therapeutic role in the treatment of neurological diseases (Table 2). We can divide the approach into two large sections, according to the role that the transplanted cells are supposed to play: substitutional and trophic.

In the early days of stem cell transplantation in neurological diseases the substitutional role was the focus of hypotheses and much optimism. Many scientific works in animal models have shown that transplanted cells lodging in the nervous tissue were not sufficient to exert any effect or to bring about any physiological outcome (Pluchino et al., 2003, 2009; Bottai et al., 2008; Cusimano et al., 2012; Nizzardo et al., 2013).

If the therapeutical approach is adopted when the neurological impairment is already substantial it is very difficult to reconstitute the tissue and, therefore, to rebuild the damaged neural circuits. Indeed, injury to the spinal cord involves the loss of

Table 2 | Stem cells used for the transplantation in neurological diseases.

\begin{tabular}{|c|c|c|}
\hline Stem cell type & Origin & References \\
\hline Embryonic stem cells & Inner cell mass of the blastocys & Evans and Kaufman, 1981; Thomson et al., 1998 \\
\hline Induced pluripotent stem cells & Reprogrammed adult tissue cells & Takahashi and Yamanaka, 2006 \\
\hline $\begin{array}{l}\text { Mesenchymal stem cells (including Amniotic } \\
\text { fluid stem cells) }\end{array}$ & $\begin{array}{l}\text { Many different tissues: bone, fat, cartilage, stromal } \\
\text { cells of the bone marrow, and fetal appendages }\end{array}$ & $\begin{array}{l}\text { De Coppi et al., 2007; Nagai et al., 2007; Bottai } \\
\text { et al., 2012; Frenette et al., } 2013\end{array}$ \\
\hline Neural stem cells & Human fetus & Weiss et al., 1996; Vescovi et al., 1999b \\
\hline Muscle stem cells & Skeletal muscle & Cooper et al., 2006 \\
\hline
\end{tabular}


motor-neurons with long axons that are surrounded by myelin sheets. In these cases the transplanted cells have to reconstitute not only the neurons but also the glia; moreover, they need to be able to extend their processes in the right direction in order to exert their therapeutic action.

With current knowledge it is unlikely that this task could be achieved but the combination of transplanting therapies and bioengineering (constructing scaffolds) could be a new avenue for transplantation research in finely structured tissues.

\section{DIFFERENT TYPES OF STEM CELLS USED FOR THE TREATMENT OF NEUROLOGICAL DISEASES}

From a physiological point of view we can divide stem cells into embryonic, fetal and adult cells (Table 2). The differences between them are in their origins, their proliferation and differentiation capabilities and their telomere stability.

\section{EMBRYONIC STEM CELLS (ESCS) AND INDUCED PLURIPOTENT STEM CELLS (iPS)}

Since the early 1980's (Evans and Kaufman, 1981) it has been well known that ESCs possess high proliferation and differentiation capabilities and were able to generate a whole mouse (Nagy et al., 1993). In the late nineties the possibility of producing human ESCs was also demonstrated (Thomson et al., 1998). Unlike normal somatic cells, ESCs do not face senescence and can be grown in virtually unlimited quantities, retaining high telomerase activity and normal cell cycle signaling.

ESCs have been used for many years in different models of neurodegenerative diseases. For instance, in 2002 Isacson demonstrated that mouse undifferentiated ESCs transplanted into the striatum of a rat model of $\mathrm{PD}$ resulted in the differentiation of Dopaminergic (DA) neurons and caused sustained behavioral restoration of motor asymmetry (Bjorklund et al., 2002). A few years later, two groups demonstrated that primate ESCs differentiated in vitro were able to induce a partial recovery in parkinsonian monkeys (Takagi et al., 2005) and rats (Ferrari et al., 2006) and were able to integrate in the striatum, generating Tyrosine Hydroxylase (TH)+ neurons. Also SCI has been treated using the transplantation of ESCs either using differentiated ESCs (such as oligodendrocytes precursors) (Liu et al., 2000), where the cells migrate and differentiate in mature oligodendrocytes capable of myelinating axons or undifferentiated cells (Bottai et al., 2010) where they have mainly a trophic role, reducing the inflammation and preserving the myelin of the ventral columns.

Retinoic acid pretreated ESCs were also successfully used in ischemic rat models (Wei et al., 2005) where they enhanced functional recovery on neurological and behavioral tests. Moreover, motor neuron differentiated ESCs were able to induce a motor improvement in a genetic rat model of ALS (Lopez-Gonzalez et al., 2009), and multipotent neural precursors (NPs) reduced the clinical signs of MS in a mouse model of experimental autoimmune encephalomyelitis by means of the attenuation of the inflammatory process (Aharonowiz et al., 2008).

Regardless of their potentiality the use of undifferentiated ESCs raises considerable numbers of concerns about the formation of tumors and teratomas, although such a risk decreases with their progressive cellular differentiation (i.e., reduced multipotency); in addition to these factors, we must not forget that there are many ethical concerns around ESCs.

In 2006 a new frontier was opened up by Yamanaka (Takahashi and Yamanaka, 2006). The production of embryonic-like stem cells originating from adult cells (mostly fibroblasts) put an end to the ethical concerns around the use of pluripotent stem cells. These induced pluripotent stem cells, obtained by the introduction of four genes Oct3/4, Sox2, c-Myc, and Klf4, which have a transcriptional factor activity in the early phases of their development, have physiological and molecular characteristics similar to ES with respect to their proliferation and differentiation potentiality. Moreover, in vivo iPS induction in mice demonstrated that in experimental conditions the iPS have an unexpected capacity to form embryo-like structures including the three germ layers and the extra-embryonic structures, indicating that induction in vivo can achieve an even earlier stage of development than the ESCs (Abad et al., 2013).

The affinity of iPS with the ESCs makes these cells suitable for a similar application in animal models of neurological pathology. Indeed, it has been demonstrated that human iPS differentiate into DA progenitor cells and transplanted into a chemically induced PD rat survive long term and develop into DA neurons and integrate into the brain parenchyma. However, some cells produced tumour-like nestin positive cells, raising some concern about the safety of these cells (Cai et al., 2010); indeed, in another study, in order to minimize the risk of tumour formation the dopaminergic derived iPS cells were separated from contaminating pluripotent cells by means of fluorescence-activated cell sorting (Wernig et al., 2008). Protein-based iPS differentiated to the terminally-matured DA neurons as the ESCs did, but had higher levels of DA neuron-specific markers' expression than ES cells, indicating that iPS were a suitable source for PD patient-specific treatment (Kwon et al., 2014).

Similarly, neuroepithelial-like stem cells from human iPS cells were used to treat SCI in mouse. In this model they were able to differentiate into neural lineage and cause a recovery of motor function (Fujimoto et al., 2012; Kobayashi et al., 2012).

Ischemia induced by middle cerebral artery occlusion was treated by means of astroglial- and neuron-like differentiated iPS using a fibrin glue support. iPS cells were able to improve the motor function, attenuate inflammation, reduce infarct size and mediate neuroprotection in this model (Chen et al., 2010).

Concerning the fetal and adult stem cells obtained from differentiated tissue in the fetus and in mature organisms, many different types of cells can be described that have some (at least preclinical) applications.

\section{NEURAL STEM CELLS}

The telencephalon and the diencephalon of the human fetus between the 9.5 and the 12th weeks of gestation possess cells with all the characteristics of stem cells. They proliferate at a ratio that could allow transplantation into human patients to treat various pathologies and can differentiate into neurons (that have physiological electrical activity), astrocytes and oligodendrocytes (Vescovi et al., 1999a) in a similar way to how neural stem cells obtained from rodents do so (Gritti et al., 1999; Bottai et al., 2003). 
Neural stem cells have been successfully applied to many different animal models of neurological diseases. They were used in an MS mouse model and induced either a substitutional effect, especially at the level of the oligodendrocytes, which were able to reconstitute the myelin sheets, or a trophic effect by means of the production of different cytokines (Pluchino et al., 2003).

The same cells were also intravenously transplanted into a mouse model of SCI and they had no capacity to rebuild the damaged tissue but they were able to reduce the inflammation through the production of neurotrophic factors (Bottai et al., 2008), indicating that the response of the same cells differs according to the pathology. Analogous results were obtained via intraspinal transplantation of neural stem cells, and in this case an immunomodulation was also obtained (Cusimano et al., 2012). On the other hand, human neural stem cells transplanted into an SOD1 rat model of ALS by means of multiple segments in the spinal cord injection have been shown to ameliorate the disease, delaying the onset and prolonging survival (Xu et al., 2011). In addition, human neural stem cells were used for the treatment of ischemia in adult rats, where they migrate and differentiate in the rat brain with focal ischemia and improve functional recovery (Chu et al., 2004b).

\section{MESENCHYMAL STEM CELLS (MSCs)}

Mesenchymal stem cells can be retrieved from various adult tissues such as fat, cartilage, stromal cells of the bone marrow, dental pulp, skin, and from fetal appendages (De Coppi et al., 2007; Bottai et al., 2012; Moroni and Fornasari, 2013). MSCs have many disadvantages (relative to ESCs or iPS) such as insufficient numbers of stem cells, reduced proliferation and differentiation capacity with age in vitro and after stem cell transplantation in vivo (Rao and Mattson, 2001). However, to date, no evidence of spontaneous transformation have been described; as a matter of fact a study which reported such an event published in 2005 (Rubio et al., 2005) was retracted in 2010 (De La Fuente et al., 2010).

These data prompted researchers to find other sources of MSC, and the search was directed to fetal tissues and in particular fetal appendages such as cord blood (Malgieri et al., 2010), amniotic fluid (De Coppi et al., 2007; Bottai et al., 2012) and placenta (Zhu et al., 2013). Results of flow cytometry revealed that cells isolated from human umbilical cords, amniotic fluid and placenta expressed CD29, CD44, CD73, CD90, and CD105, but not hematopoietic- or endothelial-specific antigens CD14, CD34, CD45, CD 106, CD 133, or HLA-DR (MHC-II) (De Coppi et al., 2007; Bottai et al., 2012; Zhu et al., 2013).

These cells can probably not have a substitutional role in neurological diseases; indeed, in many examples their contribution is mainly one of immunomodulation. The work performed by Uccelli's group is enlightening. This author has described in many papers the roles of MSCs in two neurological pathologies: MS and ALS (Lanza et al., 2009; Morando et al., 2012; Uccelli et al., 2012). The main outcome of these paper was that MSCs exert their effects by means of antioxidant and neuroprotective activity. Similar results were described in a mouse model of SCI where systemic treatment with Amniotic Fluid Stem cells (AFCs) was able to induce some recovery of motor function and partial spinal cord tissue preservation through an anti inflammatory mechanism which involved the production of the hepatocyte growth factor (Bottai et al., 2014).

\section{HOW EFFICIENTLY CAN TRANSPLANTATION IN ANIMAL MODELS BE TRANSLATED INTO USE IN TREATING HUMAN DISEASES?}

One major issue common to all types of disease is the validity of any single model or group of models (McGonigle, 2013). One attempt to provide a rigorous mode of assessment was the set of criteria proposed by Willner (1984) for use in the evaluation of an animal model for CNS disorders. In order to study a human pathology the choice of an appropriate animal model for preclinical study is required since it will allow a more feasible translation to clinical study. An ideal animal model, will have many attributes: a comparable anatomy and physiology; a similar genetic basis; close pathological response(s) and underlying mechanism(s); a phenotypic final stage similar to clinical studies; responsiveness to known drugs with clinical efficacy and predictiveness of clinical efficacy. Even when the animal model fulfills all of these criteria, in many cases translation into human trials results in difficulties or poor success rates. An understanding of the reasons why this transposition is unproductive is therefore necessary but unfortunately it has to be adapted model by model and pathology by pathology.

When a new chemical entity (NCE) is introduced for the treatment of a pathology an appropriate study of the pharmacodynamic/pharmacokinetic $(\mathrm{PD} / \mathrm{PK})$ relationships is necessary (Fan and De Lannoy, 2013). These steps are already difficult with conventional drugs since in many cases the animal model has significantly different pharmacokinetics; moreover, in many cases the pathology is not present in nature for the animal model so there can be also significant differences in the pharmacodynamics, especially in the case of transgenic and knockdown models. All these points are exponentially magnified when we are faced with a cellular approach to the pharmacologic treatment.

\section{VARIATIONS IN THE TRANSPLANTATION APPROACH}

The first issue to be taken into account in the animal model used for the pathology is of course that it has to be as close as possible to the human counterpart, but there are pathologies that do not exist in animals in nature. One example is that SMA is not present in the mouse, which has only one smn1 gene and when this is missing or is mutated this condition is not compatible with life; another example is that, monkeys have many copies of Smn1 and if one is not functional there is no appreciable effect on the animals (Bottai and Adami, 2013). So the use of these models by scientists has to be evaluated very carefully.

Another important point concerns the type of cells that should be used in the pathology. If, for example, the aim is to assess the efficacy of stem cell treatment in a mouse model of SCI, it would be wise to use mouse stem cells in order to avoid the need for immuno suppression treatment. In this case the translation to clinical trial will necessitate verification of the characteristics of the human cells, and, in many cases, their use in preclinical studies before starting phase 1 of clinical trial. 
In view of this, it seems necessary to use human stem cells from a range of sources in animal models of neurodegenerative pathology. Consequently in many situations the animal model of the human pathology needs to be treated with immunosuppressive agents in order to avoid the rejection of the transplanted cells; thus, implicitly, a new variable is introduced into the experiment and the analysis will be much more convoluted. On the other hand, some types of cells such as MSC are able to exert immunomodulatory effects and could be transplanted without immunosuppressive treatment of the animal (Dazzi et al., 2012).

\section{DIFFERENCES IN THE PREPARATION OF THE CELLS}

Initiating the clinical study brings the need to work according to Good Manufacturing Practice conditions (GMP). At this stage a large number of new culturing and transplanting settings must be introduced, which will include the appropriate laboratory facilities and the appropriate materials that are needed to achieve "human standard."

Such steps result in a very large increase in the costs of the clinical trial but they are necessary to ensure the safety of the treatments in humans. Moreover these changes in mode of preparation can, in some situations, interfere with the properties of the cells and reduce their usefulness for transplantation.

Another factor that needs to be taken in account is the mode of transplantation adopted, for instance, whether it is performed locally, regionally or systemically. This decision involves many different questions, such as how many transplantations could be performed, how many cells need to be transplanted and, consequently, how many cells must be cultivated. This last question-the number of cells needed-is of particular interest when considering the step between the preclinical and the clinical trial. While, for instance, we use $10^{6}$ neural stem cells to transplant a spinal cord injured mice (transplantation in the tail vein) (Bottai et al., 2008), for a human we will need many more cells due to the human's body weight being roughly 2000 times greater. This is quite apart from the different pharmacokinetic properties of the human organism relative to the animal; indeed, the metabolism of the mouse is much higher than the human's. For these reasons a more regional transplantation is desirable.

\section{STANDARD PROCEDURES FOR TRANSPLANTATION APPROACHES}

In summary, the choice of cells and the mode of transplantation adopted are both crucial for the successful outcome of the treatment. The diagram in Figure 1 shows a flow chart that could be followed in order to make appropriate decisions for the choice of stem cells and the method of transplantation.

In this scenario, a quality control step is needed: cells must be GMP grade; however, the analysis of their safety vis-à-vis the stability of the culture is mandatory. A karyotype, or-better- an expression panel of the cells is needed before transplantation in order to check whether the culture is stable after various passages in vitro. Moreover, in order to clarify the choice of strategy, we need to evaluate whether the cells are able to differentiate and substituted the damaged cells (if we plan to have a substitutional approach), or if they can produce growth factors (if we believe that the best approach for the pathology is a trophic intervention). In some cases, localized damage could be treated in a systemic

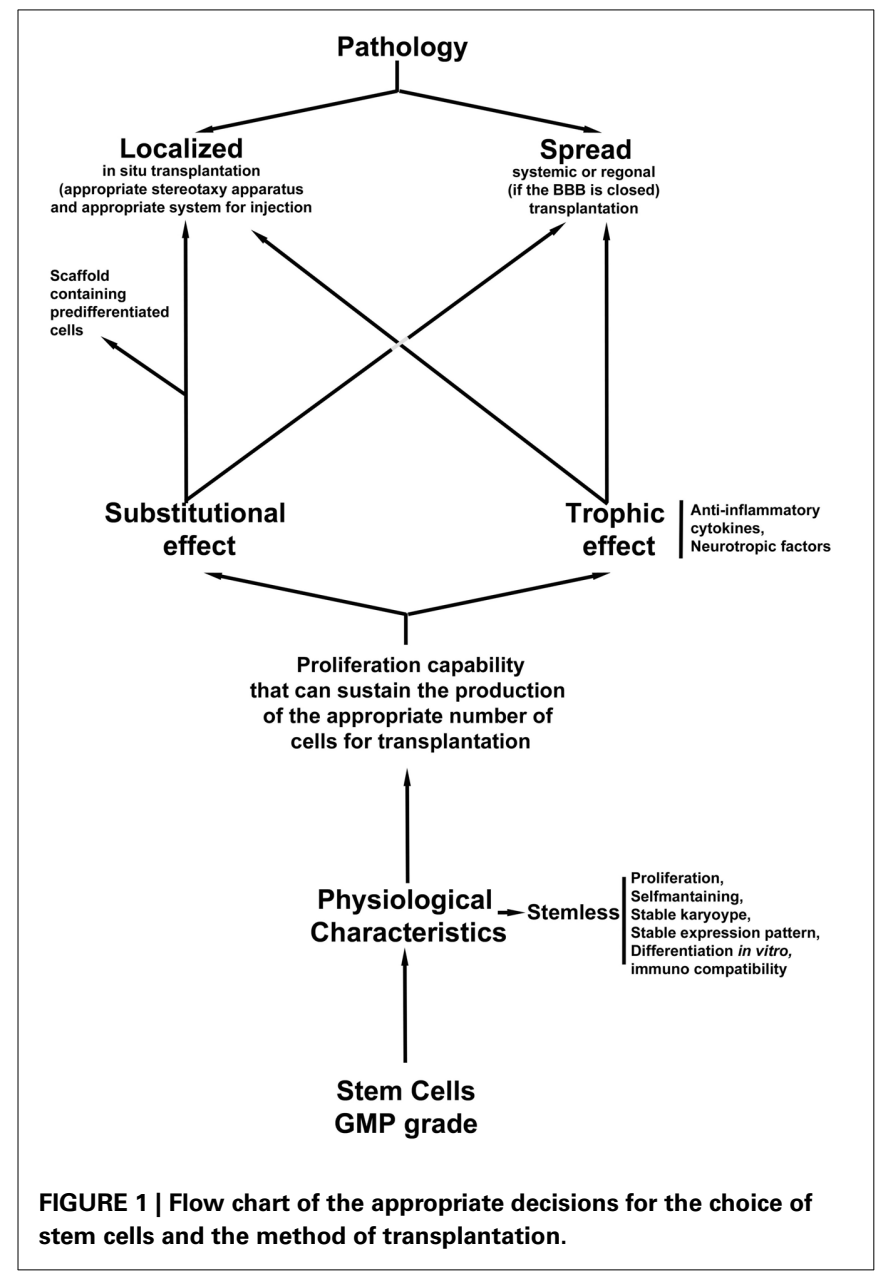

fashion as was demonstrated in an SCI animal model (Bottai et al., $2008,2010,2014$ ) where the role of the cells is mostly trophic. A third option of the transplantation strategy is the use of support scaffolds that could sustain an appropriate growth of pre differentiated stem cells if the damage is localized such as in the SCI. In this case the scaffold needs to be able to support controlled proliferation, differentiation and maturation.

Regarding the pathology, we first need to decide whether the intervention will be localized with an in situ transplantation or it will be systemic or regional. In an in situ delivery of the cells an appropriate stereotaxy apparatus will be needed (such as computed tomography $(\mathrm{CT}-)$ or Magnetic resonance imaging (MRI)-guided stereotaxic neurosurgery Brundin et al., 2000) in order to perform an injection in the correct three dimensional position, as is required for instance in transplantation in PD patients or in spinal cord injured people. On the other hand, if the pathology has affected many different sections of the CNS, a systemic or (if the BBB is not open) regional intervention could be appropriate.

\section{STEM CELL PROTOCOLS}

As mentioned above many factors need to be taken into account in dealing with the transplantation of stem cells in a pathology 
and in particular in a neurodegerative disease. The following section offers a description of the parameters that we need follow when stem cells are prepared before the transplantation, with MSCs being used as a representative example. Meanwhile we have to keep in mind that, as pharmaceutical tools stem cells are very stringently regulated: in Europe is ruled by the regulation (EC) No. 1394/2007 on Advanced Therapy Medicinal Products (ATMPs), which lays down specific guidelines concerning supervision, pharmacovigilance and centralized authorization (Martins et al., 2014).

\section{ISOLATION OF MSCs}

Because MSCs are spread widely through the human body, several different procedures can be adopted for their isolation.

Mesenchymal stem cells can be isolated from many different tissues such as fat, cartilage, stromal cells of the bone marrow, dental pulp and skin and from fetal appendages (De Girolamo et al., 2013; Moroni and Fornasari, 2013; Ikebe and Suzuki, 2014); and different strategies must be used to extract the MSCs according to which tissue is used.

For instance, the ATMPs certification is required in order to meet the guideline criteria of the International Society for Cellular Therapy (ISCT), so a specific isolation protocol for umbilical cord tissue was patented.

The procedure for bone marrow MSCs preparation comprises three steps: (a) Cells undergo an initial decontamination step using an efficient antibiotic/antimycotic, (b) All the enzymes used are clinical grade and fetal bovine serum is substituted by non-animal materials, and (c) the absence of mycoplasmaand endotoxins absences is ensured by using appropriate sample handling materials and cell culture reagents (Martins et al., 2014).

Additional, tissue dependent, steps are necessary; for example, the amounts of enzymes and cofactors needed for the dissociation of the tissue must be optimized. The first seeding steps will be performed in a non-animal free serum condition and in a static horizontal monolayer in order to allow the elimination, the following day, of the non-adherent cells, which are discarded and the medium changed. When the ATMP-adapted protocols is required the first step will be the use of plastic disposable ware and all sample handling material and cell culture materials need to be certified as mycoplasma-free and as having an acceptable low endotoxin level. Moreover, the culture must to be monitored on a regular basis for the visible detection of bacterial or fungal contaminations and for mycoplasma and endotoxin contamination using the appropriate detection kit. The ATMP cultures need to be compared with those produced under standard non GMP protocols in order to verify that their characteristics are maintained in these new conditions; for this purpose an Affymetrix GeneChip analysis on 47,000 human transcripts is desirable (Martins et al., 2014).

Another important aspect that needs attention during the preparation of cultures of ATMP grade is the flow cytometer immune phenotypic analyses. For cord blood MSC cells, the surface markers used are CD44; CD73; CD90; CD14; CD45; CD31; CD34; CD19; HLA-DR, and CD105 (Martins et al., 2014).
Two further keys points in testing of the ATMP grade of the cells are the evaluations of their differentiation capability and of their teratoma-forming potential. Adipogenic, chondrogenic and osteogenic differentiations are performed in a standardized fashion following already established protocols (Santos et al., 2013). The teratoma assay formation is performed in immunodeficient male, C.B.-17/GbmsTac-scid-bgDF N7 mice (6 weeks old), using the candidate MSCs and the ESCs H9 as positive control, implanting $1 \times 10^{4}$ cells beneath the testicular capsule; the teratoma growth is analyzed $6.5-8.5$ weeks post implantation after the sacrifice of the animal (Martins et al., 2014).

A final issue which needs particular attention for the handling of MSC cells from cord blood, but which is also relevant to all stem cells, is cryopreservation.

This procedure usually involves slow cooling in the presence of a cryoprotectant to avoid the damaging effects of intracellular ice formation. $1-2^{\circ} \mathrm{C} / \mathrm{min}$ and rapid thawing is considered standard, whereas the passive cooling devices which employ mechanical refrigerators, generally at $-80^{\circ} \mathrm{C}$, do not offer sufficient reproducibility for the ATMP-grade cells'.

Dimethyl sulphoxide (DMSO), is the most widely used cryoprotectant, but it is known to be toxic at certain temperatures, times, and concentrations to stem cells and tissue, especially if the transplanted cells are not cleaned of it before transplantation. For these reasons polyvinylpyrrolidone (PVP) has been used in order to reduce the concentration of DMSO (Hunt, 2011). In this context, the response in terms of the maintenance of stem cell characteristics depends on the type of stem cells. For example hESCs are more sensitive to conventional cooling than MSCs, with a lower recovery (16\% of viable cells after freezing and thawing) relative to MSCs and with a lower size of colonies and a significant degree of differentiation relative to the cells that had not undergone cryopreservation (Hunt, 2011).

For the cryopreservation of MSCs from bone marrow in particular the standardized number of stored cells per vial is normally $3 \times 10^{6}$. These cells have to be centrifuged at appropriate speed, then resuspended in the AMTP appropriate cryobuffer (such as $\mathrm{UCX}^{\circledR}$-ATMP in Biofreeze (Biochrome) and frozen by means of a Controlled Rate Freezer (CRF) (IceCube14S, Sylab) (Martins et al., 2014). The maintenance of the cell can be pursued in $\mathrm{N} 2$ fumes at the temperature of $-135^{\circ} \mathrm{C}$ and a specific freezing profile (Freimark et al., 2011).

A note on speeds: $200 \mathrm{~g}$ is optimal for cord blood stem cells but for different kinds of cells the speed needs to be determined, for instance NSCs that are grown in suspension as neurospheres need a lower centrifugal force to be pelleted.

Finally, a new procedure for cryopreservation is vitrification. During conventional slow cooling, ice formation and an increase of solute concentration are responsible for damage to the cells. DMSO is able to reduce such damage by reducing of the amount of ice formed. In vitrification the cryoprotectants are at a concentration that completely avoids the formation of ice crystals. This is achieved by the high concentrations of solutes and/or by rapid cooling. While cooling continues, viscosity increases until all molecular motion comes to halt and the solution becomes a glass, displaying the properties of a solid but retain the molecular structure of a liquid (Hunt, 2011). This method 
is particularly suitable for hESCs, allowing them to conserve their properties.

\section{USE OF STEM CELL TYPES IN THE ANIMAL MODEL AND IN THE HUMAN \\ EXAMPLE 1: PARKINSON'S DISEASE}

In term of complexity the damage present at the level of the $s u b$ stantia nigra is in some respects relatively low compared with other neurological disorders; indeed, a substitutional role can be hypothesized for the transplanted cells in this context. The transplantation of cells and stem cells in animal models of PD has been performed for many years. Moreover, a transplantation approach in humans affected with PD has been pursued using fetal tissue from the 5 to the 9th week post conception (Lindvall et al., 1994; Brundin et al., 2000; Kefalopoulou et al., 2014). Although these cells cannot be considered stem cells per se since they were not cultivated in vitro, the tissue of origin is rich in neural stem cells, so these experiments can be considered to be the precursors of stem cells transplantation in PD.

At the moment at least nine clinical trials are listed in the ClinicalTrials.gov site (U.S. National Institutes of Health), see Table 3. These trials make use of the knowledge gained in animal models, mostly rats (Park et al., 2008; Shetty et al., 2009; Glavaski-Joksimovic et al., 2010; Somoza et al., 2010; Blesa et al., 2012) (Table 3). The PD animal models can be divided into those using environmental or synthetic neurotoxins and those using the in vivo expression of PD-related mutations discovered in human patients (genetic). Within the neurotoxic models, compounds that produce both reversible and irreversible outcomes have been used effectively; reserpine is in the former category and the latter category there are 6-hydroxydopamine (6-OHDA), MG132 (Chung et al., 2007), MPTP (Tieu, 2011), and paraquat and rotenone which were only recently introduced (Blesa et al., 2012). However, recent studies have focused mostly on irreversible toxins to develop PD-related pathology and symptomatology. A typical property of all toxins for PD induction is their capacity to produce an oxidative stress which is most likely responsible for death in dopaminergic neuronal populations which reflects what is seen in PD. Although there are some discrepancies between the time factor in these models and the time factor in the human condition, the value of neurotoxin-based animal models in the study of PD is undeniable (Blesa et al., 2012).

The recent identification of different genetic mutations such as parkin, $\alpha$-synuclein and others has led to the development of genetic models of PD (Dawson et al., 2010); however, it is important to remember that, at most, only $10 \%$ of $\mathrm{PD}$ cases are due to genetic mutations (Dauer and Przedborski, 2003), while the majority of PD cases arise from unknown origins.

Other trials, meanwhile, were dedicated to the study of the properties of cells obtained from PD patients (as well as from other pathologies and healthy patients) (Orkin, 2000; Wei et al., 2000; Lemischka, 2001; Yu et al., 2007; Arias-Carrion and Yuan, 2009) (Table 3). These preliminary in vitro studies will allow usin the near future, we hope-to depict the molecular mechanisms of the pathology.

The effectiveness of these trials is not yet known since the results are not yet published (Table 3 ).

\section{EXAMPLE 2: AMYOTROPHIC LATERAL SCLEROSIS}

The complexity of ALS make this motor neuron disease very difficult to treat, as is confirmed by the large failure rate of clinical trials: indeed to date more than 30 clinical trials (of conventional drugs) have ended in disappointment. Increasing the odds of success for future clinical trials requires improvements in the preclinical tests. New technical advancements which allow the visualization of sick motor neurons, can bring novel insights. The development of new genetic models has brought new data about ALS and its relationship with other pathologies.

Within the mutations implicated as causative of the Familiar (F) ALS those involving the gene encoding superoxide dismutase 1 (SOD1) deserve a particular mention since they are responsible for about $20 \%$ of FALS cases (Carri et al., 2006). Indeed, many different SOD1 mouse and rat models were created, with different characteristics in terms of disease progression (onset and death), and motor performance (Carri et al., 2006). Other mutants of genes that seem to be involved in ALS have been developed, such Vegf $\delta / \delta$ and Alsin k/oas, and there have been spontaneous mutations such as Dynein (Loa, Cra1) and Wobbler (which arose as the result of a spontaneous mutation at the Institute of Animal Genetics in Edinburgh) (Carri et al., 2006). Recently, mice were developed with the mutation in the genes encoding the TAR DNA-binding protein 43 (Wegorzewska et al., 2009) and FUS/TLS (Hicks et al., 2000).

Very recently, a mouse model was established to research both the C9ORF72 disease mechanism and the possible therapy. When it is available for the scientific community this model will speed up the research on ALS.

Most of the clinical trials ongoing or already concluded make use of the preclinical trials data obtained from animal models (Yu et al., 2007; Dimos et al., 2008; Cho et al., 2010a; Choi et al., 2010b; Karussis et al., 2010; Kim et al., 2010; Blanquer et al., 2012; Koh et al., 2012a,b; Kwon et al., 2012; Robberecht and Philips, 2013) (Table 4). These studies, though, demonstrate that, so far, translation to the human ALS patient is poor. To date, from the 18 clinical trials only two publications have been produced (Glass et al., 2012; Gropp et al., 2012) and only the former really applied to the human patient, while the second concerned the preparation of iPS from cells obtained from patients (Table 4). Feldman and coworkers (Glass et al., 2012) demonstrated the safety of the treatment with Human Spinal Cord Derived Neural Stem Cells obtained from the spinal cord of a 8-week-old fetus, and included testing against many different variables. They have many adverse effects - transient encephalopathy, pulmonary emboli, CSF leak, wound dehiscence, bronchitis/pneumonia, dyspnea, atrial fibrillation, vomiting, basal cell carcinoma-which were most likely related to the injection procedure itself. No rejection markers were detected in the transplanted individuals. On the basis of these results the trial was considered "successful." Hitherto, since the stated aim of studies was to test safety in an ALS population, very little could be said about effectiveness (Glass et al., 2012). In the work led by Reubinoff (Gropp et al., 2012) a rigorous method of teratoma assay was set up in order to analyze the pluripotency of human ES cells and the biosafety of their differentiated progeny in such a way as to allow a safer translation to humans. 


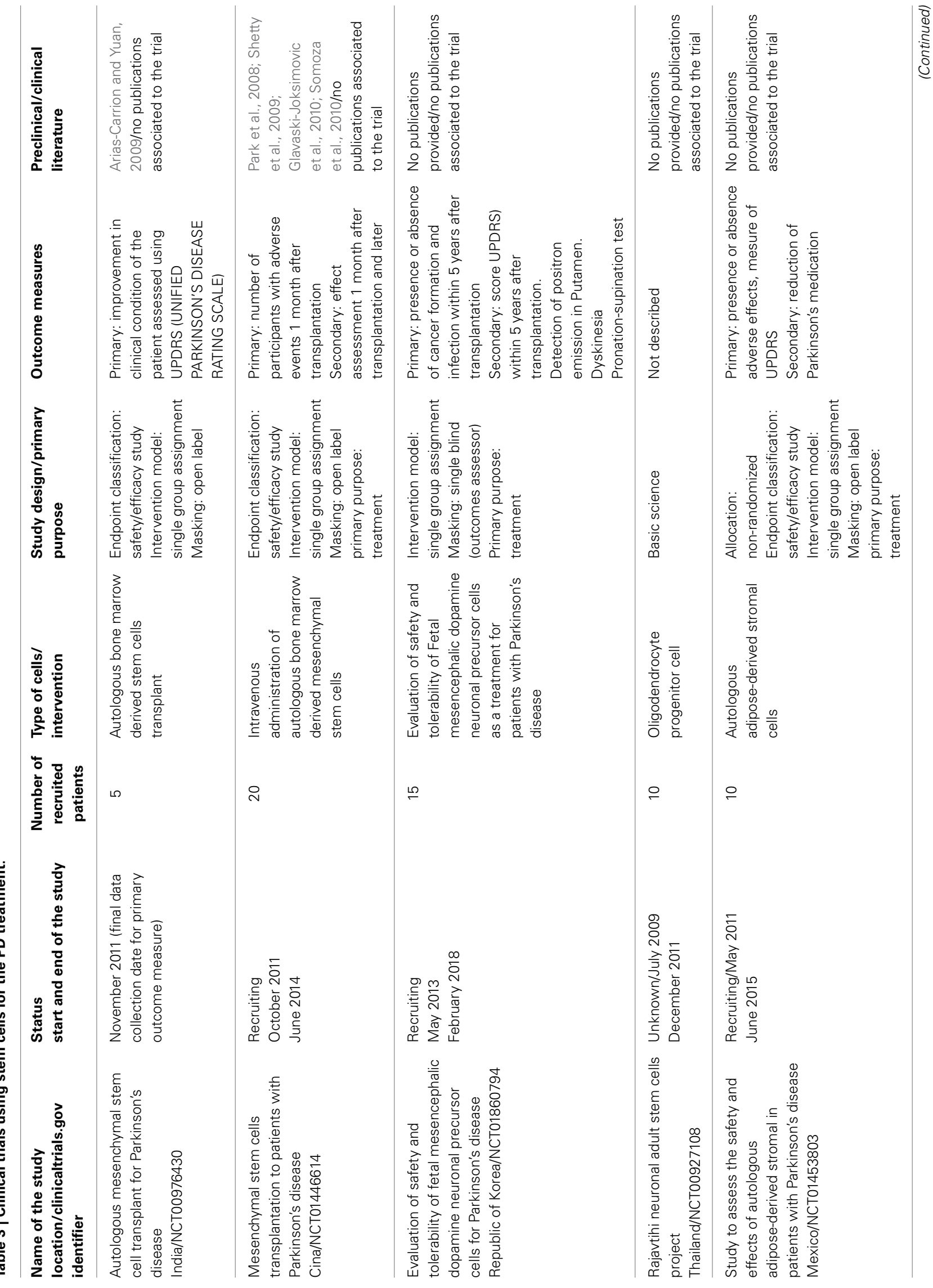




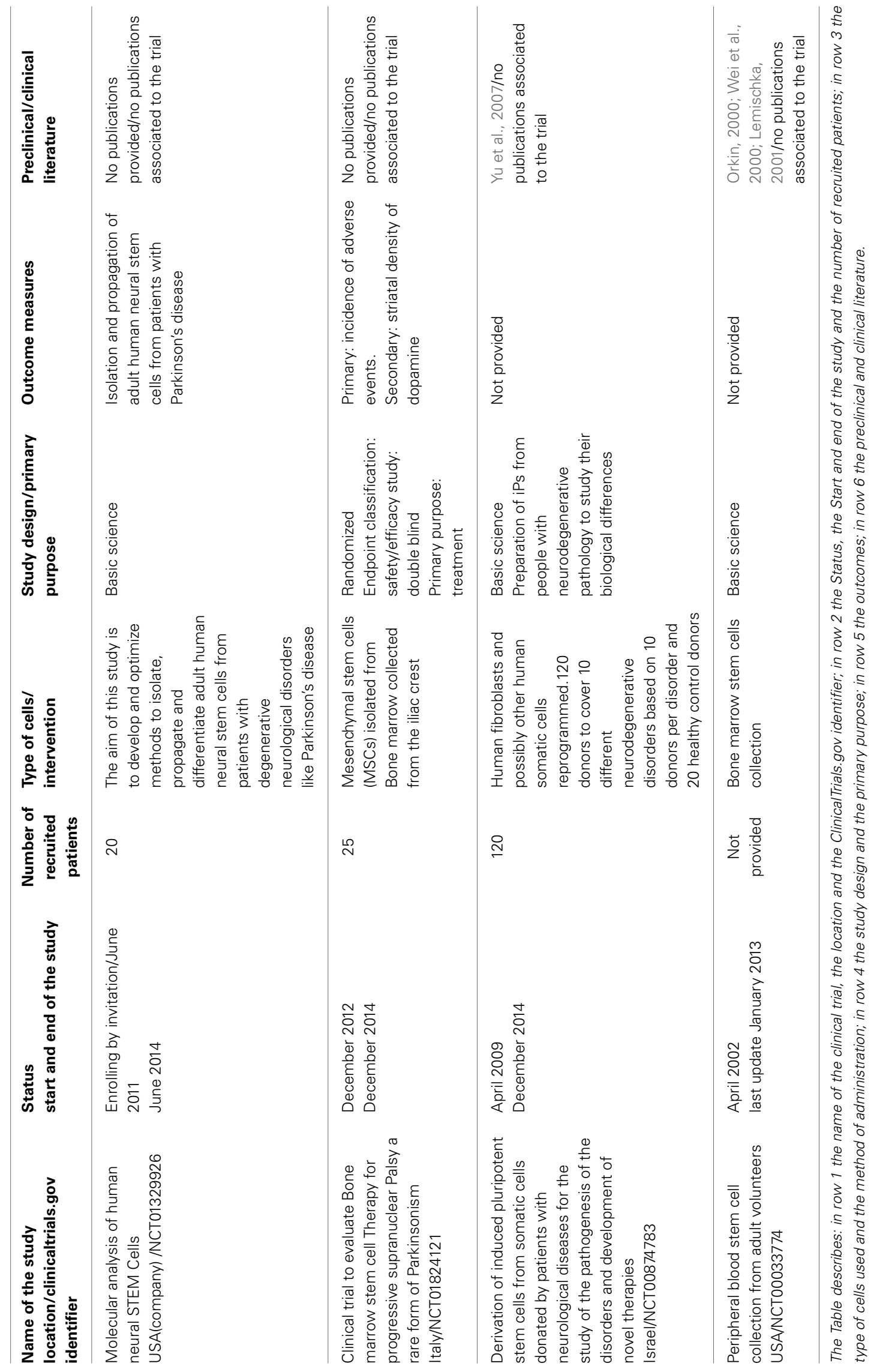




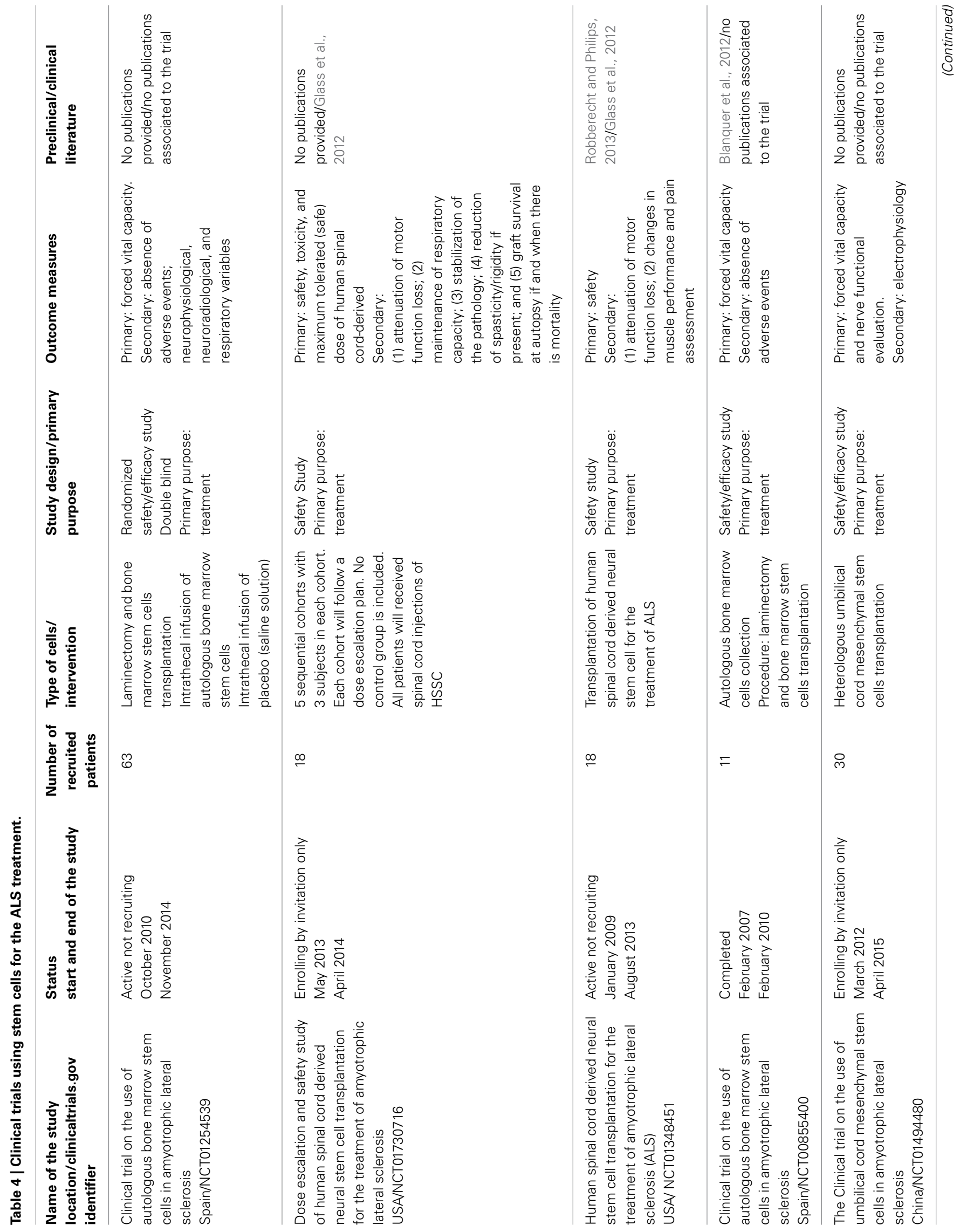




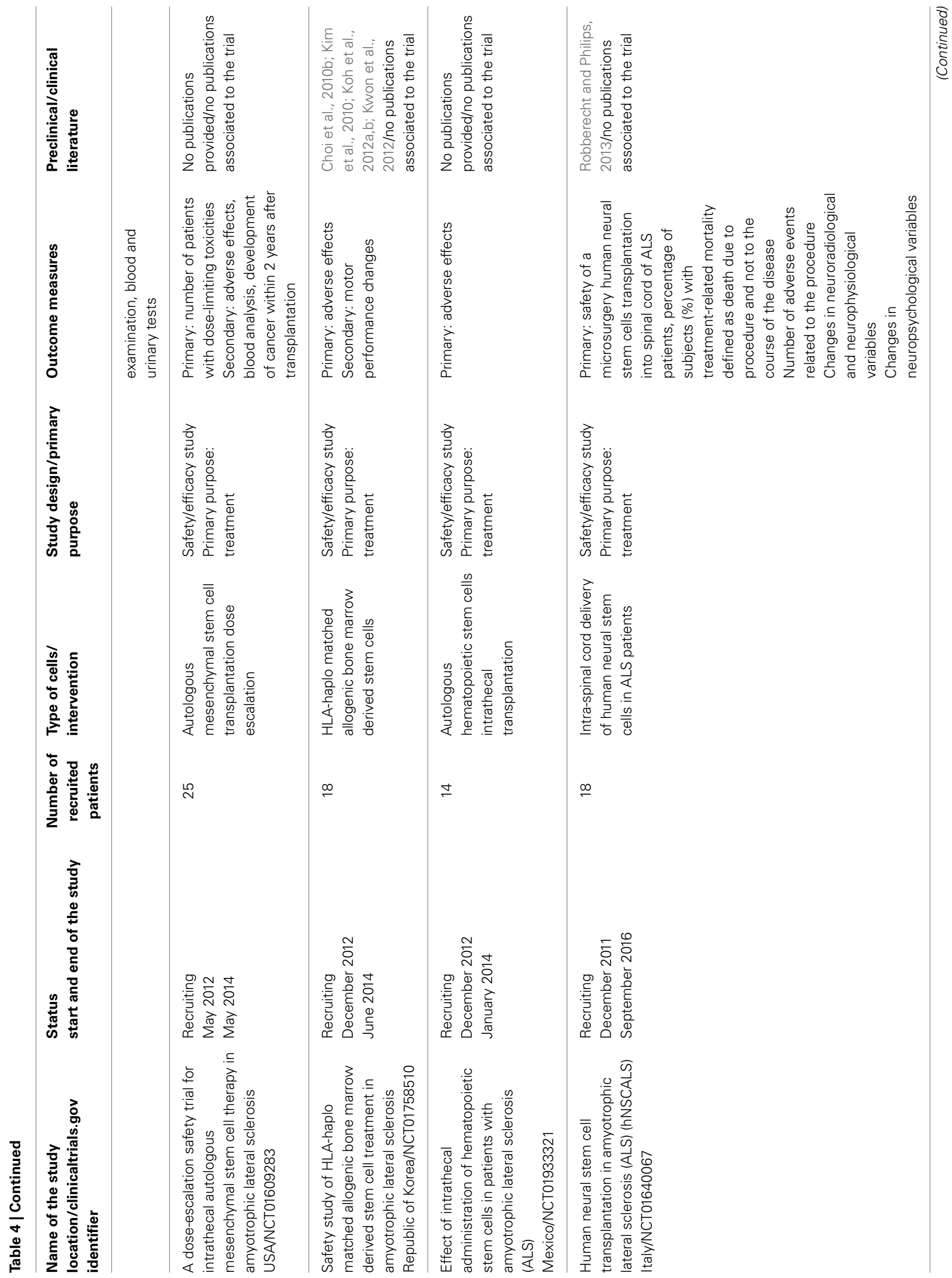




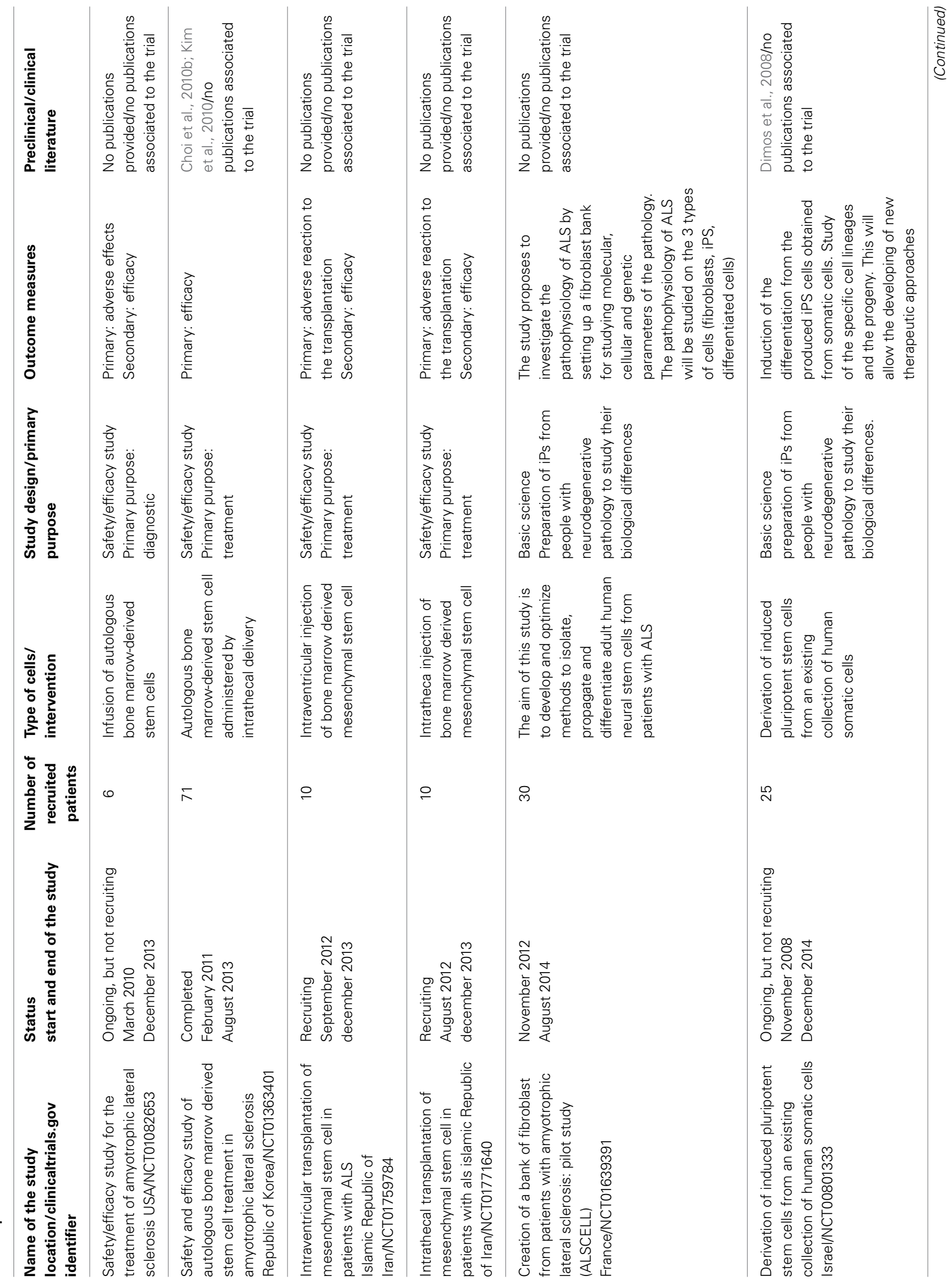




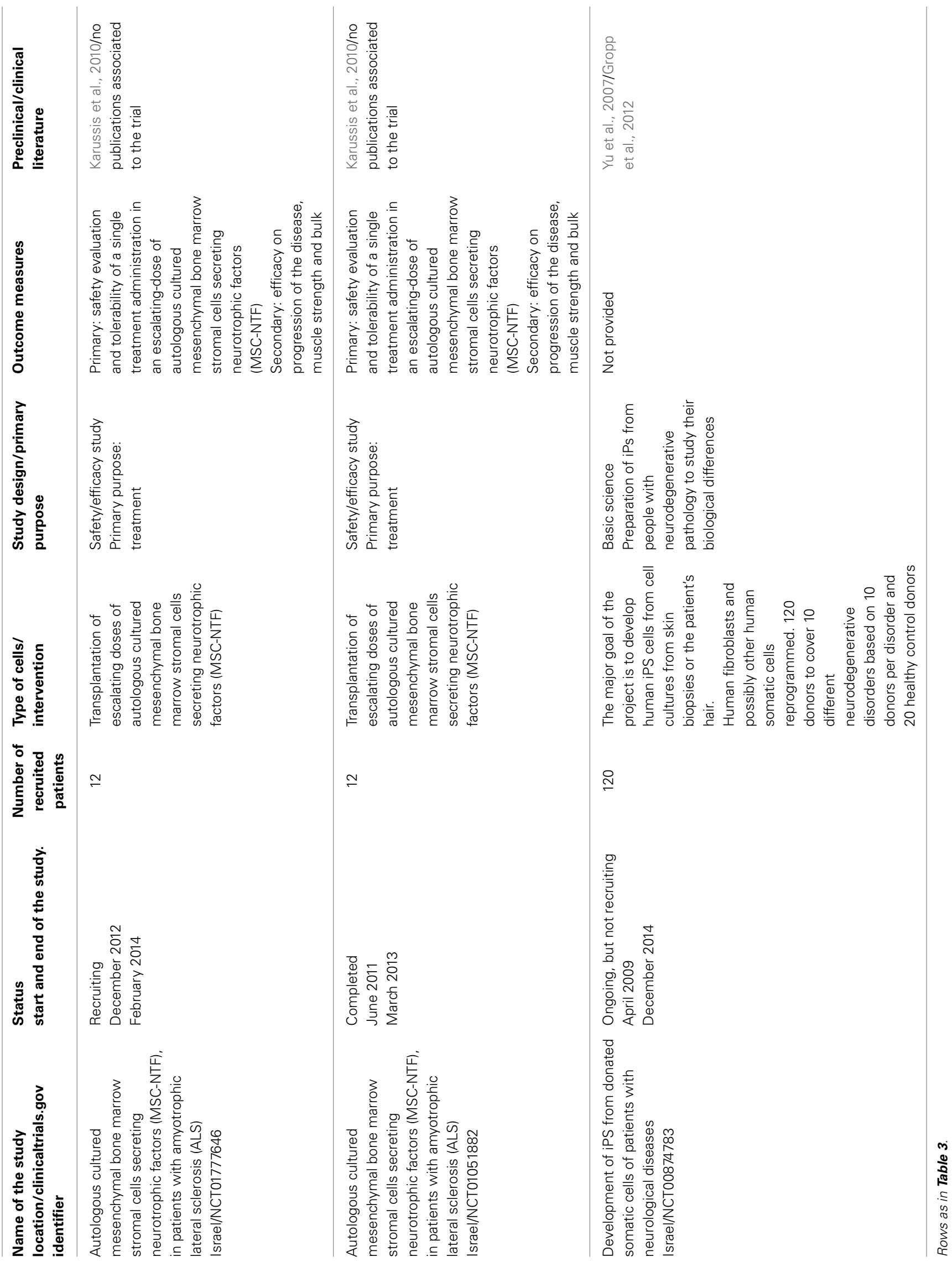


There are probably many reasons why the translation between ALS preclinical-trials and clinical trials is inefficient. The first of these is the timetable of intervention, since in many cases the risks of transplantation (with multiple injections at the spinal cord or brain level) are high and it can only be performed in a patient who is at the later stages of the disease. On this view, an earlier intervention could be more advantageous. A second reason is the type and number of cells that need to be transplanted and here the issue of safety is primary: indeed almost all the trials conducted for ALS included a phase I.

\section{EXAMPLE 3: SPINAL CORD INJURY}

Spinal cord injury is a pathological state that consists of at least of two phases: acute and chronic. Although the closest animal model to human SCI is represented by primates their use is limited in many countries, so the most frequently models are rodents: rats and mice. In these models the injury can be performed by, for instance, aortic occlusion (Lang-Lazdunski et al., 2000) or by clip compression (Von Euler et al., 1997). On the other hand, a very widely used model of SCI is the contusive approach where the laminectonize spinal cord is struck, in earlier studies, by a weight (weight drop) (Gale et al., 1985) and in later studies by a cylinder whose dimensions vary according to the type of animal and the region of the spinal cord under study, and with strength, speed and displacement-controlled (Scheff et al., 2003). The injured animal can be studied with regards to behavioral, sensorial and immunohistological factors. An early intervention could avoid the damage caused by the immune-system which is responsible for many detrimental effects, while a late intervention could be indicated if the intention is substitution. Within the 16 clinical trials reported in Table 5, six were dedicated to chronic patients (NCT01393977, NCT01772810, NCT01676441, NCT01873547, NCT01186679, and NCT00816803). The literature used for the submission of these trials includes preclinical studies on mice and rats but also takes note of previous clinical trials (Moviglia et al., 2006; Zurita and Vaquero, 2006; Parr et al., 2007; Geffner et al., 2008; Sheth et al., 2008; Cho et al., 2009; Pal et al., 2009; Paul et al., 2009; Hu et al., 2010; Osaka et al., 2010; Hernandez et al., 2011; Ra et al., 2011; Park et al., 2012). As reported for other pathologies (see Tables 3, 4) very few published works were produced; the only example we are aware of is the work obtained from trial NCT00816803 (El-Kheir et al., 2013). The main outcome of this work was that, in the group of the patients treated with cells, 17 out of 50 managed to show an improvement as measured by the American Spinal Injury Association (ASIA) Impairment Scale (AIS) (for more details see http://www.asia-spinalinjury. org/elearning/ISNCSCI_Exam_Sheet_r4.pdf.), whereas none of 20 controls not treated with cells managed to show any improvement.

Within the cell therapy subgroup of 15 patients with a baseline AIS A (complete lack of motor and sensory function below the level of injury, including the anal area), 2 patients converted to AIS C (some muscle movement is spared below the site of injury, but 50 percent of the muscles caudally to the level of injury cannot move against gravity) and 6 patients improved to AIS B (Some sensation below the level of the injury, including anal sensation). Similarly, within the cell therapy subgroup of 35 patients with a baseline AIS B, 9 patients converted to AIS C. In addition, out of 50 patients treated with cell therapy (AIS A and B), 23 patients had their ASIA motor score increased by $\geq 10$ points. The authors were encouraged by these results and they predicted that a greater number of transplantations and cells per transplantation could perhaps improve the already promising results.

\section{EXAMPLE 4: EPILEPSY}

Animal models for this pathology can be divided into two main groups: induced and genetic. The genetic models include animals with spontaneous recurrent seizure: mice or rats, epileptic dogs, transgenic mice, and animals with reflex seizure such as DBA/2 mice, gerbils and photosensitive baboons, while the induced seizure models include the electrically induced and the chemically induced (Loscher, 2011).

Only one trial with the use of stem cells in epileptic patients is indicated as ongoing in clinical trial.gov (Table 6). In this work Bone Marrow Stem Cells are used, and it builds on studies performed on animal models, mostly rats, where different kinds of stem cells-human neural fetal stem cells and neural or embryonic mouse stem cells-were used (Chu et al., 2004a; Ruschenschmidt et al., 2005). In this trial the authors used bone marrow stem cells because of their high availability and their potential role in re-establishing the normal interaction between nerve cells; no data about the effectiveness of the procedure are available yet for this trial. This approach probably does not have any substitutional role vis-a-vis the damaged or malfunctioning cells.

\section{EXAMPLE 5: STROKE}

Stroke results either from the rupture of a cerebral blood vessel or from the occlusion of a cerebral artery. As described for other pathologies, rodents such as mice and rats have been extensively used as animal models of stroke, although rabbits, pigs and primates have also been utilized. These models can be divided into two categories: those in which stroke occurs spontaneously and those in which the pathology is induced by the researcher, and this latter type can be either global or focal ischemia.

Global ischemia mimics the cerebral damage that takes place after cardiac arrest and its significance is due to the fact that the incidence of cognitive deficits in all patients that survive sudden cardiac arrest is as high as 50\% (Lim et al., 2004). An interesting, widely used model of stroke is middle cerebral artery occlusion (MCAO), produced surgically (Tamura et al., 1981) or by thromboembolic agents that mimic the most common cause of ischemic stroke in humans (Kilic et al., 1998). MCAO in rodents can induce long-term sensorimotor and cognitive deficits and postural and sensory reflexes (Bouet et al., 2007; Freret et al., 2009). Transitory MCAO permits the investigation not only of brain injury associated with ischemia, but also of the cerebral outcomes of reperfusion.

Models of sub-arachnoid hemorrhage (SAH) produce intracranial bleeds in the subarachnoid space between the arachnoid membrane and the pia mater and cause rupture of intracranial vessels that reflects the clinical condition of aneurysmal SAH in humans (Bederson et al., 1995; Veelken et al., 1995). Intracerebral hemorrhage (ICH) can be induced in an 


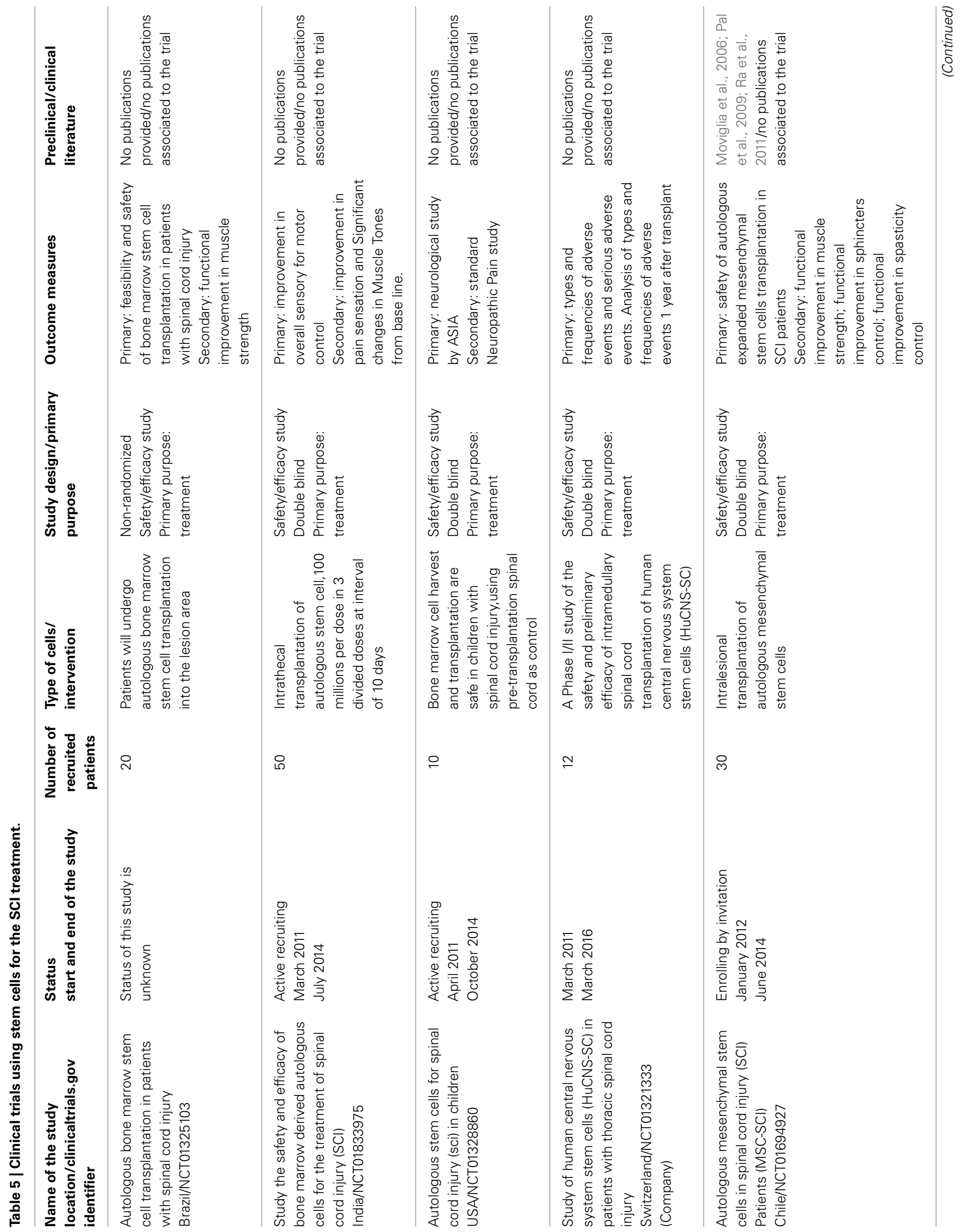




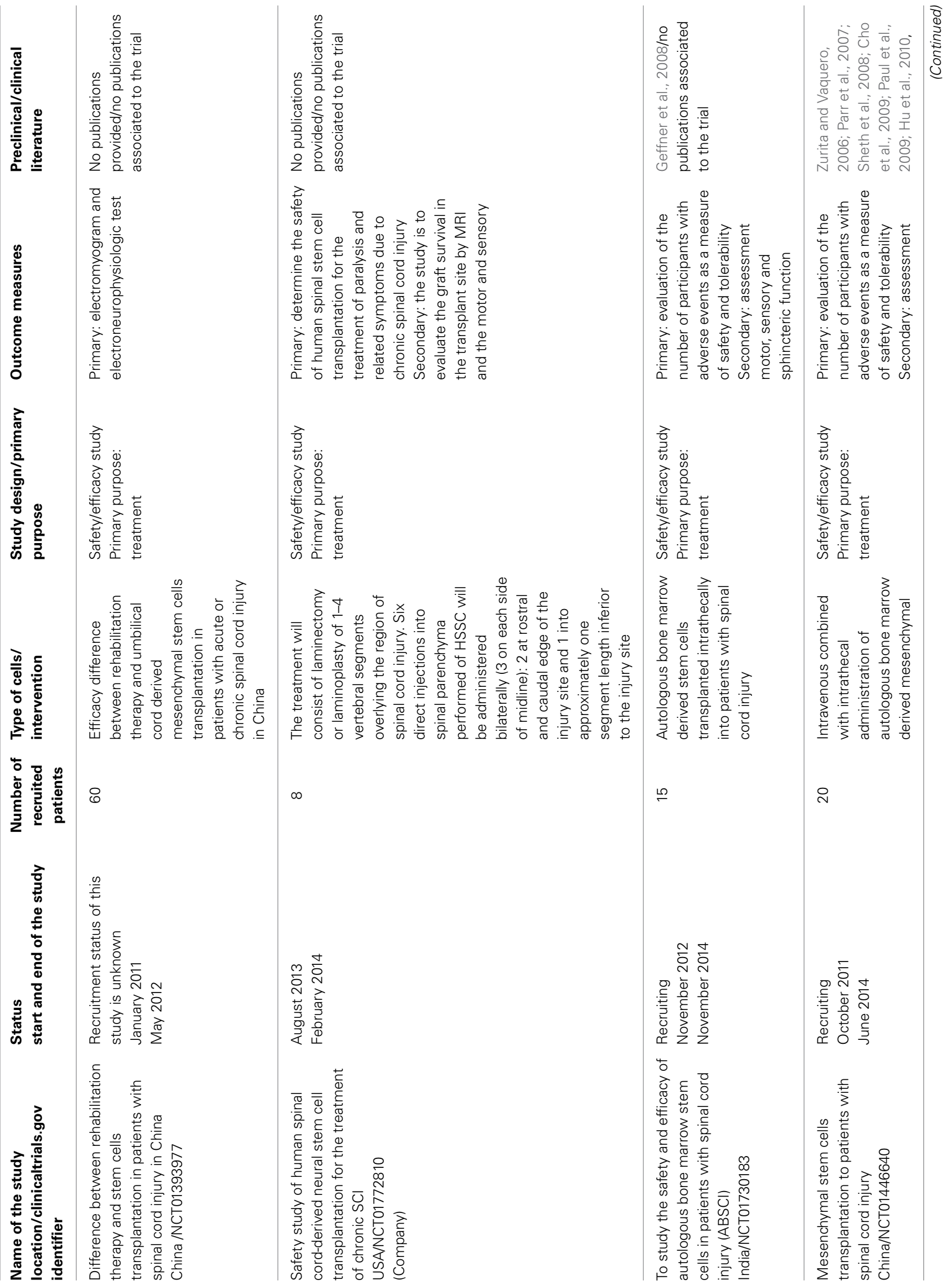




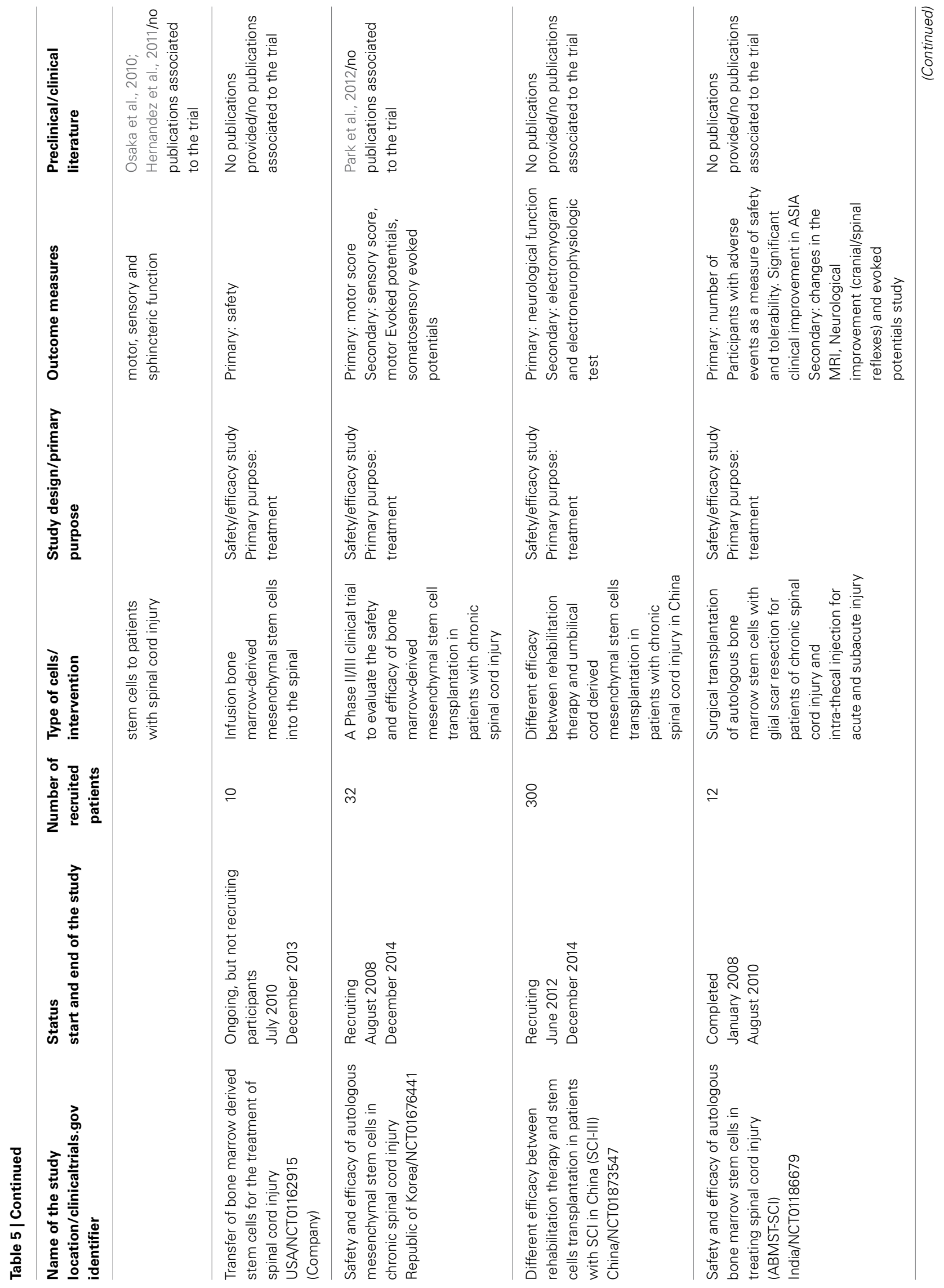




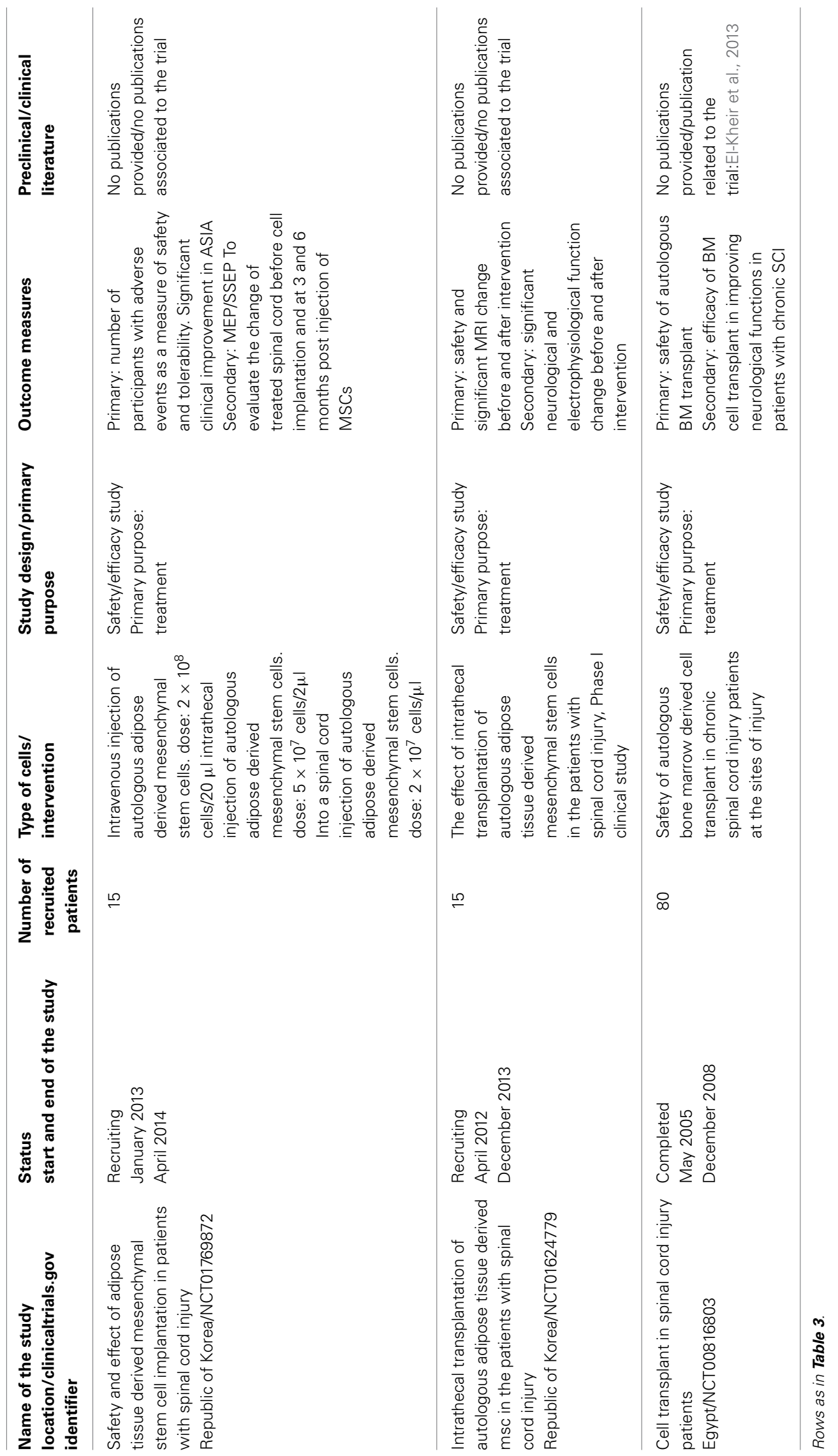




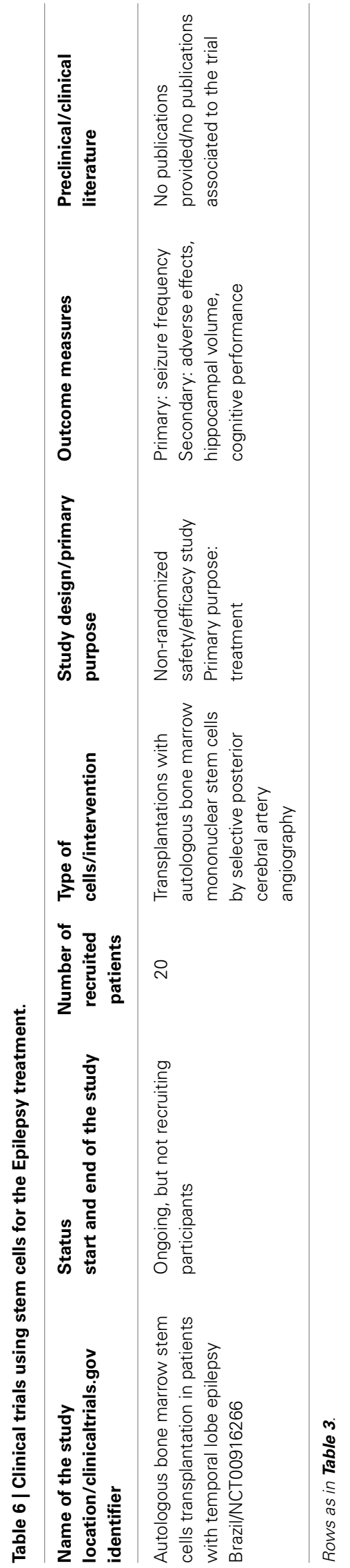

animal model by means of the intracerebral injection of bacterial collagenase, which disrupts the basal lamina of blood vessels, causing spontaneous bleeding into the surrounding brain tissue (Maclellan et al., 2008).

Spontaneous stroke models [Spontaneously Hypertensive Stroke-Prone Rat (SHRSP)] were produced as a sub strain of the spontaneously hypertensive rat (SHR). SHRSP rats develop increasing levels of blood pressure from 6 weeks of age, and stroke symptoms by 20 weeks (Bailey et al., 2011). Some transgenic animals (mostly mice) can allow the study of rare forms of stroke as a result of single gene mutations (Markus, 2011).

A variety of cellular approaches have been used for the treatment of stroke. In the nineties, fetal neocortical grafts (Grabowski et al., 1992) and fetal porcine striatal cells (Savitz et al., 2002) were used in transplantation experiments for stroke.

Several types of MSC, ESC, and NSC (Neural progenitors (NP) of human origin) have been used for the treatment of stroke in preclinical trials. For instance, it was demonstrated that human NP were able to induce behavioral improvement 5 weeks after transplantation (Jeong et al., 2003).

Many preclinical treatments of stroke induced by means of MCA occlusion were performed using Human Umbilical Cord Blood (UCB) cells, Bone Marrow Stem Cells (BM-SC) (Borlongan et al., 2011) and MSCs. These reports described various rates of survival and differentiation of the cells, mostly surrounding the ischemic boundary zone (Chen et al., 2001). Better results were obtained by permeabilizing the blood brain barrier (BBB) by means of mannitol in rats subjected to MCA with reduced infarct size, indicating that a permeable BBB is necessary for the mobilization of cells into the brain (Borlongan et al., 2004). This treatment is able to induce a behavioral recovery 2 months after intravenous transplantation (Park et al., 2009), but the mechanism involved is still not clear and it is possible that cell protection is a result of a trophic effect rather than of cell replacement or integration (Chen et al., 2001).

Extensive studies of the therapeutic potential of ES cells for transplantation in stroke indicated that predifferentiate ES cells showed very low contralateral migration and survival (Buhnemann et al., 2006), whereas immature ES cells migrated extensively after contralateral transplantation in a focal ischemic rat model (Hoehn et al., 2002).

More than 60 trials are ongoing or are completed on a stem cell approach for stroke: the completed trials are presented in Table 7. Most of them made use of the data from the previously described preclinical studies. On the basis of these results, many different trials have been carried out, mostly making use of studies of UCB cells, peripheral blood stem cells and MSCs (Mackie and Losordo, 2011). Six trials on stroke patients were accomplished before the start of 2014. Trial NCT00950521 demonstrated that peripheral blood stem cells did not cause serious adverse events during the study period and induced an improvement in three different score tests (Chen et al., 2014). Trial NCT00761982 conducted in Spain demonstrated that Autologous BM-SC transplantation, done between 5 and 9 days after stroke onset, did not cause stroke recurrence or tumor formation during follow-up, but 2 patients had one partial seizure. Unfortunately this treatment did not induce any behavioral improvements 180 days after 


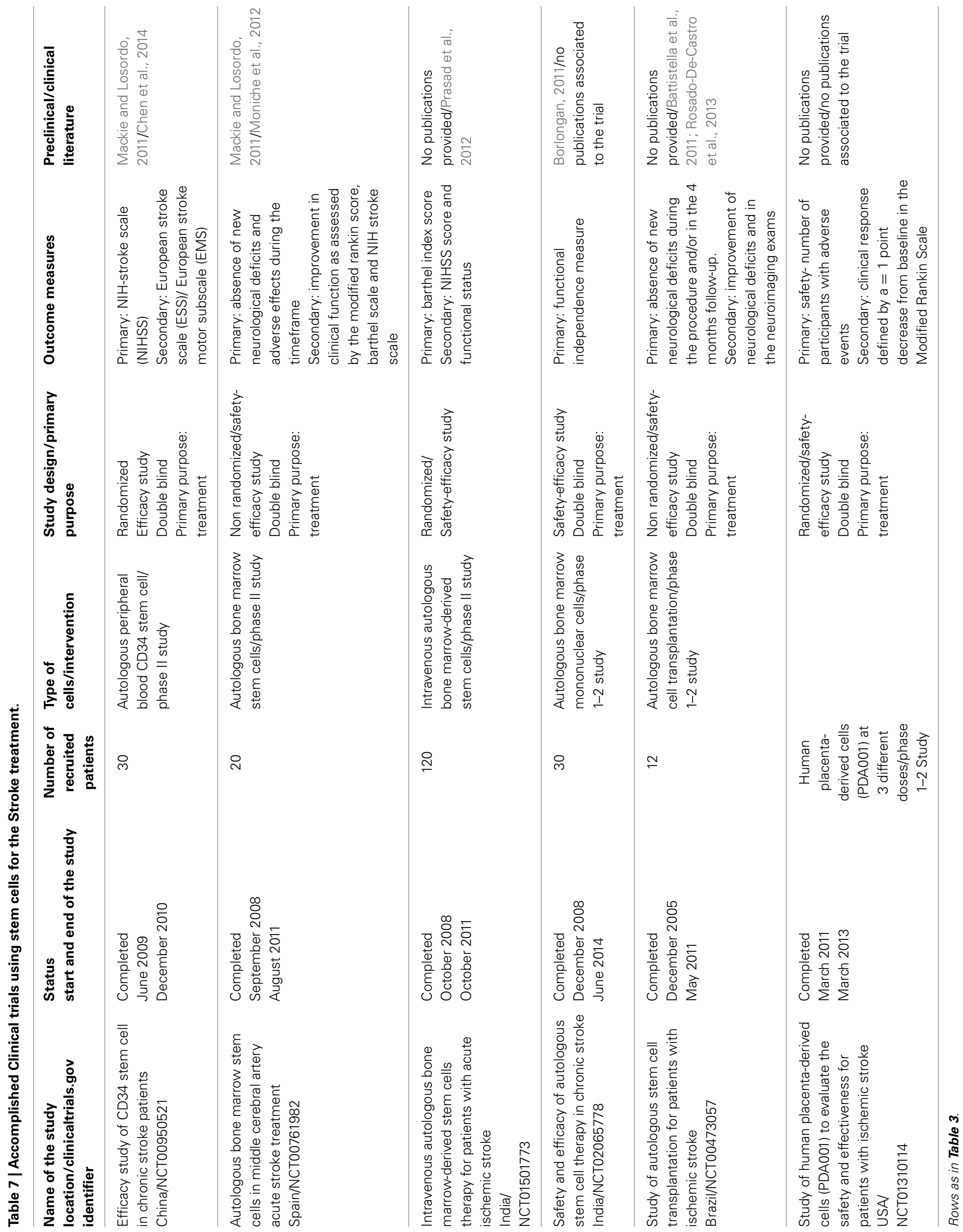


transplantation (Moniche et al., 2012). Trial NCT01501773 has not yet been summarized in a scientific paper. It is a large study which enrolled 120 patients and attempted to describe the efficacy of the Intravenous transplantation of Autologous Bone Marrowderived Stem Cells. A pilot study by the same group demonstrated that these cells were safe, but their efficacy cannot yet be established as the study was small and lacked a control group (Prasad et al., 2012).

In a Brazilian study (NCT00473057) completed in May 2011, it was shown that bone marrow cells transplanted into patients a few months after stroke did not induce signs of worsening in the neurological condition. The treatment induced an improvement trend in the National Institutes of Health Stroke Scale score for all the patients but further studies are required to better evaluate the efficacy of this therapy (Battistella et al., 2011; Rosado-De-Castro et al., 2013).

\section{CONCLUDING REMARKS}

The translation from preclinical experiments in animal models of human neurological pathologies to the treatment of humans is subject to many great difficulties because of the variability of human pathologies. When we consider the use of stem cells for treatment, the level of complexity is further increased by the extreme physiological heterogeneity of these cells and by their responses to the environment.

Since the characteristics of the pathologies cannot be changed, a major advance in stem cell therapy could be achieved by standardizing the preparation, handling and transplantation of these cells. Such improvements are indispensable to an understanding of the potential for effective translation of preclinical trials, and would significantly reduce the variability of the outcomes of clinical trials.

\section{ACKNOWLEDGMENTS}

The editing of the manuscript was performed by Damian Randle's proofreading and editorial service for the academic world and for business in the UK and Europe (http://englishedituk.co.uk). This work was supported by Vertical Foundation Via Carlo Bernari 13, 00139 Roma (IT) and by Asamsi ONLUS via Prosciutta, 23-48018 Faenza (RA), Italy to Daniele Bottai.

\section{REFERENCES}

Abad, M., Mosteiro, L., Pantoja, C., Canamero, M., Rayon, T., Ors, I., et al. (2013). Reprogramming in vivo produces teratomas and iPS cells with totipotency features. Nature 502, 340-345. doi: 10.1038/nature12586

Abrahams, S., Leigh, P. N., Kew, J. J., Goldstein, L. H., Lloyd, C. M., and Brooks, D. J. (1995). A positron emission tomography study of frontal lobe function (verbal fluency) in amyotrophic lateral sclerosis. J. Neurol. Sci. 129(Suppl.), 44-46. doi: 10.1016/0022-510X(95)00060-F

Aharonowiz, M., Einstein, O., Fainstein, N., Lassmann, H., Reubinoff, B., and BenHur, T. (2008). Neuroprotective effect of transplanted human embryonic stem cell-derived neural precursors in an animal model of multiple sclerosis. PLoS ONE 3:e3145. doi: 10.1371/journal.pone.0003145

Antony, P. M., Diederich, N. J., Kruger, R., and Balling, R. (2013). The hallmarks of Parkinson's disease. FEBS J. 280, 5981-5993. doi: 10.1111/febs. 12335

Arias-Carrion, O., and Yuan, T. F. (2009). Autologous neural stem cell transplantation: a new treatment option for Parkinson's disease? Med. Hypotheses 73, 757-759. doi: 10.1016/j.mehy.2009.04.029
Bailey, E. L., Smith, C., Sudlow, C. L., and Wardlaw, J. M. (2011). Is the spontaneously hypertensive stroke prone rat a pertinent model of sub cortical ischemic stroke? A systematic review. Int. J. Stroke 6, 434-444. doi: 10.1111/j.17474949.2011.00659.x

Battistella, V., De Freitas, G. R., Da Fonseca, L. M., Mercante, D., Gutfilen, B., Goldenberg, R. C., et al. (2011). Safety of autologous bone marrow mononuclear cell transplantation in patients with nonacute ischemic stroke. Regen. Med. 6, 45-52. doi: 10.2217/rme.10.97

Bederson, J. B., Germano, I. M., and Guarino, L. (1995). Cortical blood flow and cerebral perfusion pressure in a new noncraniotomy model of subarachnoid hemorrhage in the rat. Stroke 26, 1086-1091. discussion: 1091-1082. doi: 10.1161/01.STR.26.6.1086

Bensimon, G., Lacomblez, L., and Meininger, V. (1994). A controlled trial of riluzole in amyotrophic lateral sclerosis. ALS/Riluzole Study Group. N. Engl. J. Med. 330, 585-591. doi: 10.1056/NEJM199403033300901

Beydoun, A., and D'souza, J. (2012). Treatment of idiopathic generalized epilepsya review of the evidence. Exp. Opin. Pharmacother. 13, 1283-1298. doi: 10.1517/14656566.2012.685162

Bjorklund, L. M., Sanchez-Pernaute, R., Chung, S., Andersson, T., Chen, I. Y., McNaught, K. S., et al. (2002). Embryonic stem cells develop into functional dopaminergic neurons after transplantation in a Parkinson rat model. Proc. Natl. Acad. Sci. U.S.A. 99, 2344-2349. doi: 10.1073/pnas.022438099

Blanquer, M., Moraleda, J. M., Iniesta, F., Gomez-Espuch, J., Meca-Lallana, J., Villaverde, R., et al. (2012). Neurotrophic bone marrow cellular nests prevent spinal motoneuron degeneration in amyotrophic lateral sclerosis patients: a pilot safety study. Stem Cells 30, 1277-1285. doi: 10.1002/stem.1080

Blesa, J., Phani, S., Jackson-Lewis, V., and Przedborski, S. (2012). Classic and new animal models of Parkinson's disease. J. Biomed. Biotechnol. 2012, 845618. doi: $10.1155 / 2012 / 845618$

Borlongan, C. V. (2011). Bone marrow stem cell mobilization in stroke: a 'bonehead' may be good after all! Leukemia 25, 1674-1686. doi: 10.1038/leu.2011.167

Borlongan, C. V., Glover, L. E., Tajiri, N., Kaneko, Y., and Freeman, T. B. (2011). The great migration of bone marrow-derived stem cells toward the ischemic brain: therapeutic implications for stroke and other neurological disorders. Prog. Neurobiol. 95, 213-228. doi: 10.1016/j.pneurobio.2011.08.005

Borlongan, C. V., Hadman, M., Sanberg, C. D., and Sanberg, P. R. (2004). Central nervous system entry of peripherally injected umbilical cord blood cells is not required for neuroprotection in stroke. Stroke 35, 2385-2389. doi: 10.1161/01.STR.0000141680.49960.d7

Bottai, D., and Adami, R. (2013). Spinal muscular atrophy: new findings for an old pathology. Brain Pathol. 23, 613-622. doi: 10.1111/bpa.12071

Bottai, D., Cigognini, D., Madaschi, L., Adami, R., Nicora, E., Menarini, M., et al. (2010). Embryonic stem cells promote motor recovery and affect inflammatory cell infiltration in spinal cord injured mice. Exp. Neurol. 223, 452-463. doi: 10.1016/j.expneurol.2010.01.010

Bottai, D., Cigognini, D., Nicora, E., Moro, M., Grimoldi, M. G., Adami, R., et al. (2012). Third trimester amniotic fluid cells with the capacity to develop neural phenotypes and with heterogeneity among sub-populations. Restor. Neurol. Neurosci. 30, 55-68. doi: 10.3233/RNN-2011-0620

Bottai, D., Fiocco, R., Gelain, F., Defilippis, L., Galli, R., Gritti, A., et al. (2003). Neural stem cells in the adult nervous system. J. Hematother. Stem Cell Res. 12, 655-670. doi: 10.1089/15258160360732687

Bottai, D., Madaschi, L., Di Giulio, A. M., and Gorio, A. (2008). Viabilitydependent promoting action of adult neural precursors in spinal cord injury. Mol. Med. 14, 634-644. doi: 10.2119/2008-00077.Bottai

Bottai, D., Scesa, G., Cigognini, D., Adami, R., Nicora, E., Abrignani, S., et al. (2014). Third trimester NG2-positive amniotic fluid cells are effective in improving repair in spinal cord injury. Exp. Neurol. 254, 121-133. doi: 10.1016/ j.expneurol.2014.01.015

Bouet, V., Freret, T., Toutain, J., Divoux, D., Boulouard, M., and SchumannBard, P. (2007). Sensorimotor and cognitive deficits after transient middle cerebral artery occlusion in the mouse. Exp. Neurol. 203, 555-567. doi: 10.1016/j.expneurol.2006.09.006

Breitenstein, C., Floel, A., Korsukewitz, C., Wailke, S., Bushuven, S., and Knecht, S. (2006). A shift of paradigm: from noradrenergic to dopaminergic modulation of learning? J. Neurol. Sci. 248, 42-47. doi: 10.1016/j.jns.2006.05.012

Brown, T. P., Rumsby, P. C., Capleton, A. C., Rushton, L., and Levy, L. S. (2006). Pesticides and Parkinson's disease-is there a link? Environ. Health Perspect. 114, 156-164. doi: 10.1289/ehp.8095 
Brundin, P., Pogarell, O., Hagell, P., Piccini, P., Widner, H., Schrag, A., et al. (2000). Bilateral caudate and putamen grafts of embryonic mesencephalic tissue treated with lazaroids in Parkinson's disease. Brain 123(Pt 7), 1380-1390. doi: 10.1093/brain/123.7.1380

Buhnemann, C., Scholz, A., Bernreuther, C., Malik, C. Y., Braun, H., Schachner, M., et al. (2006). Neuronal differentiation of transplanted embryonic stem cellderived precursors in stroke lesions of adult rats. Brain 129, 3238-3248. doi: 10.1093/brain/awl261

Burglen, L., Lefebvre, S., Clermont, O., Burlet, P., Viollet, L., Cruaud, C., et al. (1996). Structure and organization of the human survival motor neurone (SMN) gene. Genomics 32, 479-482. doi: 10.1006/geno.1996.0147

Burglen, L., Spiegel, R., Ignatius, J., Cobben, J. M., Landrieu, P., Lefebvre, S., et al. (1995). SMN gene deletion in variant of infantile spinal muscular atrophy. Lancet 346, 316-317. doi: 10.1016/S0140-6736(95)92206-7

Cai, J., Yang, M., Poremsky, E., Kidd, S., Schneider, J. S., and Iacovitti, L. (2010). Dopaminergic neurons derived from human induced pluripotent stem cells survive and integrate into 6-OHDA-lesioned rats. Stem Cells Dev. 19, 1017-1023. doi: $10.1089 / \mathrm{scd} .2009 .0319$

Campbell, L., Potter, A., Ignatius, J., Dubowitz, V., and Davies, K. (1997). Genomic variation and gene conversion in spinal muscular atrophy: implications for disease process and clinical phenotype. Am. J. Hum. Genet. 61, 40-50. doi: $10.1086 / 513886$

Carri, M. T., Grignaschi, G., and Bendotti, C. (2006). Targets in ALS: designing multidrug therapies. Trends Pharmacol. Sci. 27, 267-273. doi: 10.1016/j.tips.2006.03.009

Chen, D. C., Lin, S. Z., Fan, J. R., Lin, C. H., Lee, W., Lin, C. C., et al. (2014). Intracerebral implantation of autologous peripheral blood stem cells in stroke patients: a randomized Phase II study. Cell Transplant. doi: 10.3727/096368914 X678562. [Epub ahead of print].

Chen, J., Sanberg, P. R., Li, Y., Wang, L., Lu, M., Willing, A. E., et al. (2001). Intravenous administration of human umbilical cord blood reduces behavioral deficits after stroke in rats. Stroke 32, 2682-2688. doi: 10.1161/hs1101.098367

Chen, S. J., Chang, C. M., Tsai, S. K., Chang, Y. L., Chou, S. J., Huang, S. S., et al. (2010). Functional improvement of focal cerebral ischemia injury by subdural transplantation of induced pluripotent stem cells with fibrin glue. Stem Cells Dev. 19, 1757-1767. doi: 10.1089/scd.2009.0452

Cherry, J. J., and Androphy, E. J. (2012). Therapeutic strategies for the treatment of spinal muscular atrophy. Future Med. Chem. 4, 1733-1750. doi: 10.4155/fmc. 12.107

Cho, G. W., Koh, S. H., Kim, M. H., Yoo, A. R., Noh, M. Y., Oh, S., et al. (2010). The neuroprotective effect of erythropoietin-transduced human mesenchymal stromal cells in an animal model of ischemic stroke. Brain Res. 1353, 1-13. doi: 10.1016/j.brainres.2010.06.013

Cho, S. R., Kim, Y. R., Kang, H. S., Yim, S. H., Park, C. I., Min, Y. H., et al. (2009). Functional recovery after the transplantation of neurally differentiated mesenchymal stem cells derived from bone barrow in a rat model of spinal cord injury. Cell Transplant. 18, 1359-1368. doi: 10.3727/096368909X475329

Choi, M. R., Kim, H. Y., Park, J. Y., Lee, T. Y., Baik, C. S., Chai, Y. G., et al. (2010). Selection of optimal passage of bone marrow-derived mesenchymal stem cells for stem cell therapy in patients with amyotrophic lateral sclerosis. Neurosci. Lett. 472, 94-98. doi: 10.1016/j.neulet.2010.01.054

Chu, K., Kim, M., Jung, K. H., Jeon, D., Lee, S. T., Kim, J., et al. (2004a). Human neural stem cell transplantation reduces spontaneous recurrent seizures following pilocarpine-induced status epilepticus in adult rats. Brain Res. 1023, 213-221. doi: 10.1016/j.brainres.2004.07.045

Chu, K., Kim, M., Park, K. I., Jeong, S. W., Park, H. K., Jung, K. H., et al. (2004b). Human neural stem cells improve sensorimotor deficits in the adult rat brain with experimental focal ischemia. Brain Res. 1016, 145-153. doi: 10.1016/j.brainres.2004.04.038

Chung, C. Y., Koprich, J. B., Endo, S., and Isacson, O. (2007). An endogenous serine/threonine protein phosphatase inhibitor, G-substrate, reduces vulnerability in models of Parkinson's disease. J. Neurosci. 27, 8314-8323. doi: 10.1523/JNEUROSCI.1972-07.2007

Cooper, R. N., Butler-Browne, G. S., and Mouly, V. (2006). Human muscle stem cells. Curr. Opin. Pharmacol. 6, 295-300. doi: 10.1016/j.coph.2006. 01.007

Cummings, J. L., Banks, S. J., Gary, R. K., Kinney, J. W., Lombardo, J. M., Walsh, R. R., et al. (2013). Alzheimer's disease drug development: translational neuroscience strategies. CNS Spectr. 18, 128-138. doi: 10.1017/S1092852913000023
Cusimano, M., Biziato, D., Brambilla, E., Donega, M., Alfaro-Cervello, C., Snider, S., et al. (2012). Transplanted neural stem/precursor cells instruct phagocytes and reduce secondary tissue damage in the injured spinal cord. Brain 135, 447-460. doi: 10.1093/brain/awr339

Dauer, W., and Przedborski, S. (2003). Parkinson's disease: mechanisms and models. Neuron 39, 889-909. doi: 10.1016/S0896-6273(03)00568-3

Dawson, T. M., Ko, H. S., and Dawson, V. L. (2010). Genetic animal models of Parkinson's disease. Neuron 66, 646-661. doi: 10.1016/j.neuron.2010.04.034

Dazzi, F., Lopes, L., and Weng, L. (2012). Mesenchymal stromal cells: a key player in 'innate tolerance'? Immunology 137, 206-213. doi: 10.1111/j.13652567.2012.03621.x

De Coppi, P., Bartsch, G. Jr., Siddiqui, M. M., Xu, T., Santos, C. C., Perin, L., et al. (2007). Isolation of amniotic stem cell lines with potential for therapy. Nat. Biotechnol. 25, 100-106. doi: 10.1038/nbt1274

De Girolamo, L., Lucarelli, E., Alessandri, G., Avanzini, M. A., Bernardo, M. E., Biagi, E., et al. (2013). Mesenchymal stem/stromal cells: a new "cells as drugs" paradigm. Efficacy and critical aspects in cell therapy. Curr. Pharm. Des. 19, 2459-2473. doi: 10.2174/1381612811319130015

Dejesus-Hernandez, M., Mackenzie, I. R., Boeve, B. F., Boxer, A. L., Baker, M., Rutherford, N. J., et al. (2011). Expanded GGGGCC hexanucleotide repeat in noncoding region of C9ORF72 causes chromosome 9p-linked FTD and ALS. Neuron 72, 245-256. doi: 10.1016/j.neuron.2011.09.011

De La Fuente, R., Bernad, A., Garcia-Castro, J., Martin, M. C., and Cigudosa, J. C. (2010). Retraction: spontaneous human adult stem cell transformation. Cancer Res. 70, 6682. doi: 10.1158/0008-5472.CAN-10-2451

Dimos, J. T., Rodolfa, K. T., Niakan, K. K., Weisenthal, L. M., Mitsumoto, H., Chung, W., et al. (2008). Induced pluripotent stem cells generated from patients with ALS can be differentiated into motor neurons. Science 321, 1218-1221. doi: $10.1126 /$ science. 1158799

Double, K. L. (2012). Neuronal vulnerability in Parkinson's disease. Parkinsonism Relat. Disord. 18(Suppl. 1), S52-S54. doi: 10.1016/S1353-8020(11)70018-9

El-Kheir, W. A., Gabr, H., Awad, M. R., Ghannam, O., Barakat, Y., Farghali, H. A., et al. (2013). Autologous bone marrow-derived cell therapy combined with physical therapy induces functional improvement in chronic spinal cord injury patients. Cell Transplant. 23, 729-745. doi: 10.3727/096368913X664540

Evans, M. J., and Kaufman, M. H. (1981). Establishment in culture of pluripotential cells from mouse embryos. Nature 292, 154-156.

Fan, J., and De Lannoy, I. A. (2013). Pharmacokinetics. Biochem. Pharmacol. 87, 93-120. doi: 10.1016/j.bcp.2013.09.007

Fernandez, O., Arnal-Garcia, C., Arroyo-Gonzalez, R., Brieva, L., CallesHernandez, M. C., Casanova-Estruch, B., et al. (2013). Review of the novelties presented at the 28th Congress of the European Committee for Treatment and Research in Multiple Sclerosis (ECTRIMS) (III). Rev. Neurol. 57, 317-329.

Ferrari, D., Sanchez-Pernaute, R., Lee, H., Studer, L., and Isacson, O. (2006). Transplanted dopamine neurons derived from primate ES cells preferentially innervate DARPP-32 striatal progenitors within the graft. Eur. J. Neurosci. 24, 1885-1896. doi: 10.1111/j1460-9568.2006.05093.x

Ferreira, J. J., Katzenschlager, R., Bloem, B. R., Bonuccelli, U., Burn, D., Deuschl, G., et al. (2013). Summary of the recommendations of the EFNS/MDS-ES review on therapeutic management of Parkinson's disease. Eur. J. Neurol. 20, 5-15. doi: 10.1111/j.1468-1331.2012.03866.x

Ferri, C. P., Prince, M., Brayne, C., Brodaty, H., Fratiglioni, L., Ganguli, M., et al. (2005). Global prevalence of dementia: a Delphi consensus study. Lancet 366, 2112-2117. doi: 10.1016/S0140-6736(05)67889-0

Feuerstein, G. Z., Wang, X., and Barone, F. C. (1998). The role of cytokines in the neuropathology of stroke and neurotrauma. Neuroimmunomodulation 5 , 143-159. doi: 10.1159/000026331

Fitzmaurice, A. G., Rhodes, S. L., Cockburn, M., Ritz, B., and Bronstein, J. M. (2014). Aldehyde dehydrogenase variation enhances effect of pesticides associated with Parkinson disease. Neurology 82, 419-426. doi: 10.1212/WNL.0000000000000083

Freimark, D., Sehl, C., Weber, C., Hudel, K., Czermak, P., Hofmann, N., et al. (2011). Systematic parameter optimization of a Me(2)SO- and serum-free cryopreservation protocol for human mesenchymal stem cells. Cryobiology 63, 67-75. doi: 10.1016/j.cryobiol.2011.05.002

Frenette, P. S., Pinho, S., Lucas, D., and Scheiermann, C. (2013). Mesenchymal stem cell: keystone of the hematopoietic stem cell niche and a stepping-stone for regenerative medicine. Annu. Rev. Immunol. 31, 285-316. doi: 10.1146/annurevimmunol-032712-095919 
Freret, T., Bouet, V., Leconte, C., Roussel, S., Chazalviel, L., Divoux, D., et al. (2009). Behavioral deficits after distal focal cerebral ischemia in mice: usefulness of adhesive removal test. Behav. Neurosci. 123, 224-230. doi: 10.1037/ a0014157

Fujimoto, Y., Abematsu, M., Falk, A., Tsujimura, K., Sanosaka, T., Juliandi, B., et al. (2012). Treatment of a mouse model of spinal cord injury by transplantation of human induced pluripotent stem cell-derived long-term self-renewing neuroepithelial-like stem cells. Stem Cells 30, 1163-1173. doi: $10.1002 /$ stem. 1083

Gale, K., Kerasidis, H., and Wrathall, J. R. (1985). Spinal cord contusion in the rat: behavioral analysis of functional neurologic impairment. Exp. Neurol. 88, 123-134. doi: 10.1016/0014-4886(85)90118-9

Gao, H. M., and Hong, J. S. (2011). Gene-environment interactions: key to unraveling the mystery of Parkinson's disease. Prog. Neurobiol. 94, 1-19. doi: 10.1016/j.pneurobio.2011.03.005

Garbes, L., Heesen, L., Holker, I., Bauer, T., Schreml, J., Zimmermann, K., et al. (2013). VPA response in SMA is suppressed by the fatty acid translocase CD36. Hum. Mol. Genet. 22, 398-407. doi: 10.1093/hmg/dds437

Geffner, L. F., Santacruz, P., Izurieta, M., Flor, L., Maldonado, B., Auad, A. H., et al. (2008). Administration of autologous bone marrow stem cells into spinal cord injury patients via multiple routes is safe and improves their quality of life: comprehensive case studies. Cell Transplant. 17, 1277-1293. doi: $10.3727 / 096368908787648074$

Glass, J. D., Boulis, N. M., Johe, K., Rutkove, S. B., Federici, T., Polak, M., et al. (2012). Lumbar intraspinal injection of neural stem cells in patients with amyotrophic lateral sclerosis: results of a phase I trial in 12 patients. Stem Cells 30, 1144-1151. doi: 10.1002/stem.1079

Glavaski-Joksimovic, A., Virag, T., Mangatu, T. A., McGrogan, M., Wang, X. S., and Bohn, M. C. (2010). Glial cell line-derived neurotrophic factor-secreting genetically modified human bone marrow-derived mesenchymal stem cells promote recovery in a rat model of Parkinson's disease. J. Neurosci. Res. 88, 2669-2681. doi: 10.1002/jnr.22435

Grabowski, M., Brundin, P., and Johansson, B. B. (1992). Fetal neocortical grafts implanted in adult hypertensive rats with cortical infarcts following a middle cerebral artery occlusion: ingrowth of afferent fibers from the host brain. Exp. Neurol. 116, 105-121. doi: 10.1016/0014-4886(92) 90159-N

Gritti, A., Frolichsthal-Schoeller, P., Galli, R., Parati, E. A., Cova, L., Pagano, S. F., et al. (1999). Epidermal and fibroblast growth factors behave as mitogenic regulators for a single multipotent stem cell-like population from the subventricular region of the adult mouse forebrain. J. Neurosci. 19, 3287-3297.

Gropp, M., Shilo, V., Vainer, G., Gov, M., Gil, Y., Khaner, H., et al. (2012). Standardization of the teratoma assay for analysis of pluripotency of human ES cells and biosafety of their differentiated progeny. PLoS ONE 7:e45532. doi: 10.1371/journal.pone.0045532

Grossman, A. W., and Broderick, J. P. (2013). Advances and challenges in treatment and prevention of ischemic stroke. Ann. Neurol. 74, 363-372. doi: 10.1002/ana.23993

Hernandez, J., Torres-Espin, A., and Navarro, X. (2011). Adult stem cell transplants for spinal cord injury repair: current state in preclinical research. Curr. Stem Cell Res. Ther. 6, 273-287. doi: 10.2174/157488811796575323

Hicks, G. G., Singh, N., Nashabi, A., Mai, S., Bozek, G., Klewes, L., et al. (2000). Fus deficiency in mice results in defective B-lymphocyte development and activation, high levels of chromosomal instability and perinatal death. Nat. Genet. 24, 175-179. doi: 10.1038/72842

Hoehn, M., Kustermann, E., Blunk, J., Wiedermann, D., Trapp, T., Wecker, S., et al. (2002). Monitoring of implanted stem cell migration in vivo: a highly resolved in vivo magnetic resonance imaging investigation of experimental stroke in rat. Proc. Natl. Acad. Sci. U.S.A. 99, 16267-16272. doi: 10.1073/pnas.242 435499

Howard, P., Twycross, R., Shuster, J., Mihalyo, M., Remi, J., and Wilcock, A. (2011). Anti-epileptic drugs. J. Pain Symptom Manage. 42, 788-804. doi: 10.1016/j.jpainsymman.2011.10.007

Hu, S. L., Luo, H. S., Li, J. T., Xia, Y. Z., Li, L., Zhang, L. J., et al. (2010). Functional recovery in acute traumatic spinal cord injury after transplantation of human umbilical cord mesenchymal stem cells. Crit. Care Med. 38, 2181-2189. doi: 10.1097/CCM.0b013e3181f17c0e

Hunt, C. J. (2011). Cryopreservation of human stem cells for clinical application: a review. Transfus. Med. Hemother. 38, 107-123. doi: 10.1159/000326623
Hurlbert, R. J., Hadley, M. N., Walters, B. C., Aarabi, B., Dhall, S. S., Gelb, D. E., et al. (2013). Pharmacological therapy for acute spinal cord injury. Neurosurgery 72(Suppl. 2), 93-105. doi: 10.1227/NEU.0b013e31827765c6

Ikebe, C., and Suzuki, K. (2014). Mesenchymal stem cells for regenerative therapy: optimization of cell preparation protocols. Biomed. Res. Int. 2014, 951512. doi: $10.1155 / 2014 / 951512$

Jankovic, J. (2008). Parkinson's disease: clinical features and diagnosis. J. Neurol. Neurosurg. Psychiatry 79, 368-376. doi: 10.1136/jnnp.2007.131045

Jeong, S. W., Chu, K., Jung, K. H., Kim, S. U., Kim, M., and Roh, J. K. (2003). Human neural stem cell transplantation promotes functional recovery in rats with experimental intracerebral hemorrhage. Stroke 34, 2258-2263. doi: 10.1161/01.STR.0000083698.20199.1F

Kabashi, E., Valdmanis, P. N., Dion, P., Spiegelman, D., McConkey, B. J., Vande Velde, C., et al. (2008). TARDBP mutations in individuals with sporadic and familial amyotrophic lateral sclerosis. Nat. Genet. 40, 572-574. doi: 10.1038/ng.132

Karussis, D., Karageorgiou, C., Vaknin-Dembinsky, A., Gowda-Kurkalli, B., Gomori, J. M., Kassis, I., et al. (2010). Safety and immunological effects of mesenchymal stem cell transplantation in patients with multiple sclerosis and amyotrophic lateral sclerosis. Arch. Neurol. 67, 1187-1194. doi: 10.1001/archneurol.2010.248

Kefalopoulou, Z., Politis, M., Piccini, P., Mencacci, N., Bhatia, K., Jahanshahi, M., et al. (2014). Long-term clinical outcome of fetal cell transplantation for parkinson disease: two case reports. JAMA Neurol. 71, 83-87. doi: 10.1001/jamaneurol.2013.4749

Kilic, E., Hermann, D. M., and Hossmann, K. A. (1998). A reproducible model of thromboembolic stroke in mice. Neuroreport 9, 2967-2970. doi: 10.1097/00001756-199809140-00009

Kim, H., Kim, H. Y., Choi, M. R., Hwang, S., Nam, K. H., Kim, H. C., et al. (2010). Dose-dependent efficacy of ALS-human mesenchymal stem cells transplantation into cisterna magna in SOD1-G93A ALS mice. Neurosci. Lett. 468, 190-194. doi: 10.1016/j.neulet.2009.10.074

Kobayashi, Y., Okada, Y., Itakura, G., Iwai, H., Nishimura, S., Yasuda, A., et al. (2012). Pre-evaluated safe human iPSC-derived neural stem cells promote functional recovery after spinal cord injury in common marmoset without tumorigenicity. PLoS ONE 7:e52787. doi: 10.1371/journal.pone. 0052787

Koch, M. W., Metz, L. M., and Kovalchuk, O. (2013). Epigenetics and miRNAs in the diagnosis and treatment of multiple sclerosis. Trends Mol. Med. 19, 23-30. doi: 10.1016/j.molmed.2012.10.008

Koh, S. H., Baik, W., Noh, M. Y., Cho, G. W., Kim, H. Y., Kim, K. S., et al. (2012a). The functional deficiency of bone marrow mesenchymal stromal cells in ALS patients is proportional to disease progression rate. Exp. Neurol. 233, 472-480. doi: 10.1016/j.expneurol.2011.11.021

Koh, S. H., Huh, Y. M., Noh, M. Y., Kim, H. Y., Kim, K. S., Lee, E. S., et al. (2012b). beta-PIX is critical for transplanted mesenchymal stromal cell migration. Stem Cells Dev. 21, 1989-1999. doi: 10.1089/scd.2011.0430

Kwiatkowski, T. J. Jr., Bosco, D. A., Leclerc, A. L., Tamrazian, E., Vanderburg, C. R., Russ, C., et al. (2009). Mutations in the FUS/TLS gene on chromosome 16 cause familial amyotrophic lateral sclerosis. Science 323, 1205-1208. doi: 10.1126/science.1166066

Kwon, M. J., Baek, W., Ki, C. S., Kim, H. Y., Koh, S. H., Kim, J. W., et al. (2012). Screening of the SOD1, FUS, TARDBP, ANG, and OPTN mutations in Korean patients with familial and sporadic ALS. Neurobiol. Aging 33, 1017.e171017.e23. doi: 10.1016/j.neurobiolaging.2011.12.003

Kwon, Y. W., Chung, Y. J., Kim, J., Lee, H. J., Park, J., Roh, T. Y., et al. (2014). Comparative study of efficacy of dopaminergic neuron differentiation between embryonic stem cell and protein-based induced pluripotent stem cell. PLoS ONE 9:e85736. doi: 10.1371/journal.pone.0085736

Lacomblez, L., Bensimon, G., Leigh, P. N., Guillet, P., Powe, L., Durrleman, S., et al. (1996). A confirmatory dose-ranging study of riluzole in ALS. ALS/Riluzole Study Group-II. Neurology 47, S242-S250.

Lang-Lazdunski, L., Matsushita, K., Hirt, L., Waeber, C., Vonsattel, J. P., Moskowitz, M. A., et al. (2000). Spinal cord ischemia. Development of a model in the mouse. Stroke 31, 208-213. doi: 10.1016/j.eplepsyres.2005.07.014

Lanza, C., Morando, S., Voci, A., Canesi, L., Principato, M. C., Serpero, L. D., et al. (2009). Neuroprotective mesenchymal stem cells are endowed with a potent antioxidant effect in vivo. J. Neurochem. 110, 1674-1684. doi: 10.1111/j 1471-4159.2009.06268.x 
Lemischka, I. (2001). Stem cell dogmas in the genomics era. Rev. Clin. Exp. Hematol. 5, 15-25. doi: 10.1046/j.1468-0734.2001.00030.x

Leppik, I. E., Kelly, K. M., Detoledo-Morrell, L., Patrylo, P. R., Delorenzo, R. J., Mathern, G. W., et al. (2006). Basic research in epilepsy and aging. Epilepsy Res. 68(Suppl. 1), S21-S37. doi: 10.1016/j.eplepsyres.2005.07.014

Lim, C., Alexander, M. P., Lafleche, G., Schnyer, D. M., and Verfaellie, M. (2004). The neurological and cognitive sequelae of cardiac arrest. Neurology 63 , 1774-1778. doi: 10.1212/01.WNL.0000144189.83077.8E

Lindvall, O., Sawle, G., Widner, H., Rothwell, J. C., Bjorklund, A., Brooks, D., et al. (1994). Evidence for long-term survival and function of dopaminergic grafts in progressive Parkinson's disease. Ann. Neurol. 35, 172-180. doi: 10.1002/ana.410350208

Liu, S., Qu, Y., Stewart, T. J., Howard, M. J., Chakrabortty, S., Holekamp, T. F., et al. (2000). Embryonic stem cells differentiate into oligodendrocytes and myelinate in culture and after spinal cord transplantation Proc. Natl. Acad. Sci. U.S.A. 97, 6126-6131. doi: 10.1073/pnas.97.11.6126

Lomen-Hoerth, C., Murphy, J., Langmore, S., Kramer, J. H., Olney, R. K., and Miller, B. (2003). Are amyotrophic lateral sclerosis patients cognitively normal? Neurology 60, 1094-1097. doi: 10.1212/01.WNL.0000055861.95202.8D

Lopez-Gonzalez, R., Kunckles, P., and Velasco, I. (2009). Transient recovery in a rat model of familial amyotrophic lateral sclerosis after transplantation of motor neurons derived from mouse embryonic stem cells. Cell Transplant. 18, 1171-1181. doi: 10.3727/096368909X12483162197123

Loscher, W. (2011). Critical review of current animal models of seizures and epilepsy used in the discovery and development of new antiepileptic drugs. Seizure 20, 359-368. doi: 10.1016/j.seizure.2011.01.003

Luessi, F., Siffrin, V., and Zipp, F. (2012). Neurodegeneration in multiple sclerosis: novel treatment strategies. Exp. Rev. Neurother. 12, 1061-1076. doi: $10.1586 / \mathrm{ern} .12 .59$

Mackie, A. R., and Losordo, D. W. (2011). CD34-positive stem cells: in the treatment of heart and vascular disease in human beings. Tex. Heart Inst. J. 38 , 474-485.

Maclellan, C. L., Silasi, G., Poon, C. C., Edmundson, C. L., Buist, R., Peeling, J., et al. (2008). Intracerebral hemorrhage models in rat: comparing collagenase to blood infusion. J. Cereb. Blood Flow Metab. 28, 516-525. doi: 10.1038/sj.jcbfm. 9600548

Malgieri, A., Kantzari, E., Patrizi, M. P., and Gambardella, S. (2010). Bone marrow and umbilical cord blood human mesenchymal stem cells: state of the art. Int. J. Clin. Exp. Med. 3, 248-269

Manyam, B. V., and Sanchez-Ramos, J. R. (1999). Traditional and complementary therapies in Parkinson's disease. Adv. Neurol. 80, 565-574.

Markus, H. S. (2011). Stroke genetics. Hum. Mol. Genet. 20, R124-R131. doi: $10.1093 / \mathrm{hmg} / \mathrm{ddr} 345$

Marta, M., and Giovannoni, G. (2012). Disease modifying drugs in multiple sclerosis: mechanisms of action and new drugs in the horizon. CNS Neurol. Disord. Drug Targets 11, 610-623. doi: 10.2174/187152712801661301

Martins, J. P., Santos, J. M., De Almeida, J. M., Filipe, M. A., De Almeida, M. V., Almeida, S. C., et al. (2014). Towards an advanced therapy medicinal product based on mesenchymal stromal cells isolated from the umbilical cord tissue quality and safety data. Stem Cell Res. Ther. 5, 9. doi: 10.1186/scrt398

Mattson, R. H. (2003). Overview: idiopathic generalized epilepsies. Epilepsia 44(Suppl. 2), 2-6. doi: 10.1046/j.1528-1157.44.s.2.3.x

McGonigle, P. (2013). Animal models of CNS disorders. Biochem. Pharmacol. 87, 140-149. doi: 10.1016/j.bcp.2013.06.016

Mercuri, E., Bertini, E., and Iannaccone, S. T. (2012). Childhood spinal muscular atrophy: controversies and challenges. Lancet Neurol. 11, 443-452. doi: 10.1016/S1474-4422(12)70061-3

Moniche, F., Gonzalez, A., Gonzalez-Marcos, J. R., Carmona, M., Pinero, P., Espigado, I., et al. (2012). Intra-arterial bone marrow mononuclear cells in ischemic stroke: a pilot clinical trial. Stroke 43, 2242-2244. doi: 10.1161/STROKEAHA.112.659409

Morando, S., Vigo, T., Esposito, M., Casazza, S., Novi, G., Principato, M. C., et al. (2012). The therapeutic effect of mesenchymal stem cell transplantation in experimental autoimmune encephalomyelitis is mediated by peripheral and central mechanisms. Stem Cell Res. Ther. 3, 3. doi: 10.1186/scrt94

Moroni, L., and Fornasari, P. M. (2013). Human mesenchymal stem cells: a bank perspective on the isolation, characterization and potential of alternative sources for the regeneration of musculoskeletal tissues. J. Cell. Physiol. 228, 680-687. doi: $10.1002 / j c p .24223$
Morren, J. A., and Galvez-Jimenez, N. (2012). Current and prospective diseasemodifying therapies for amyotrophic lateral sclerosis. Exp. Opin. Investig. Drugs 21, 297-320. doi: 10.1517/13543784.2012.657303

Moviglia, G. A., Fernandez Vina, R., Brizuela, J. A., Saslavsky, J., Vrsalovic, F., Varela, G., et al. (2006). Combined protocol of cell therapy for chronic spinal cord injury. Report on the electrical and functional recovery of two patients. Cytotherapy 8, 202-209. doi: 10.1080/14653240600736048

Munoz-Culla, M., Irizar, H., and Otaegui, D. (2013). The genetics of multiple sclerosis: review of current and emerging candidates. Appl. Clin. Genet. 6, 63-73. doi: 10.2147/TACG.S29107

Nagai, A., Kim, W. K., Lee, H. J., Jeong, H. S., Kim, K. S., Hong, S. H., et al. (2007). Multilineage potential of stable human mesenchymal stem cell line derived from fetal marrow. PLoS ONE 2:e1272. doi: 10.1371/journal.pone.0001272

Nagy, A., Rossant, J., Nagy, R., Abramow-Newerly, W., and Roder, J. C. (1993). Derivation of completely cell culture-derived mice from early-passage embryonic stem cells. Proc. Natl. Acad. Sci. U.S.A. 90, 8424-8428

Neary, D., Snowden, J. S., and Mann, D. M. (2000). Cognitive change in motor neurone disease/amyotrophic lateral sclerosis (MND/ALS). J. Neurol. Sci. 180, 15-20. doi: 10.1016/S0022-510X(00)00425-1

Nizzardo, M., Simone, C., Rizzo, F., Ruggieri, M., Salani, S., Riboldi, G., et al. (2013). Minimally invasive transplantation of iPSC-derived ALDHhiSSCloVLA4+ neural stem cells effectively improves the phenotype of an amyotrophic lateral sclerosis model. Hum. Mol. Genet. 23, 342-354. doi: $10.1093 / \mathrm{hmg} / \mathrm{ddt} 425$

Noseworthy, J. H., Lucchinetti, C., Rodriguez, M., and Weinshenker, B. G. (2000). Multiple sclerosis. N. Engl. J. Med. 343, 938-952. doi: 10.1056/NEJM200009283431307

Nylander, A., and Hafler, D. A. (2012). Multiple sclerosis. J. Clin. Invest. 122, 1180-1188. doi: 10.1172/JCI58649

Orkin, S. H. (2000). Diversification of haematopoietic stem cells to specific lineages. Nat. Rev. Genet. 1, 57-64. doi: 10.1038/35049577

Osaka, M., Honmou, O., Murakami, T., Nonaka, T., Houkin, K., Hamada, H., et al. (2010). Intravenous administration of mesenchymal stem cells derived from bone marrow after contusive spinal cord injury improves functional outcome. Brain Res. 1343, 226-235. doi: 10.1016/j.brainres.2010.05.011

Pal, R., Venkataramana, N. K., Bansal, A., Balaraju, S., Jan, M., Chandra, R., et al. (2009). Ex vivo-expanded autologous bone marrow-derived mesenchymal stromal cells in human spinal cord injury/paraplegia: a pilot clinical study. Cytotherapy 11, 897-911. doi: 10.3109/14653240903253857

Park, D. H., Borlongan, C. V., Willing, A. E., Eve, D. J., Cruz, L. E., Sanberg, C. D., et al. (2009). Human umbilical cord blood cell grafts for brain ischemia. Cell Transplant. 18, 985-998. doi: 10.3727/096368909X471279

Park, H. J., Lee, P. H., Bang, O. Y., Lee, G., and Ahn, Y. H. (2008). Mesenchymal stem cells therapy exerts neuroprotection in a progressive animal model of Parkinson's disease. J. Neurochem. 107, 141-151. doi: 10.1111/j.14714159.2008.05589.x

Park, J. H., Kim, D. Y., Sung, I. Y., Choi, G. H., Jeon, M. H., Kim, K. K., et al. (2012). Long-term results of spinal cord injury therapy using mesenchymal stem cells derived from bone marrow in humans. Neurosurgery 70, 1238-1247. discussion: 1247. doi: $10.1227 /$ NEU.0b013e31824387f 9

Parr, A. M., Tator, C. H., and Keating, A. (2007). Bone marrow-derived mesenchymal stromal cells for the repair of central nervous system injury. Bone Marrow Transplant. 40, 609-619. doi: 10.1038/sj.bmt.1705757

Paul, C., Samdani, A. F., Betz, R. R., Fischer, I., and Neuhuber, B. (2009). Grafting of human bone marrow stromal cells into spinal cord injury: a comparison of delivery methods. Spine (Phila Pa 1976) 34, 328-334. doi: 10.1097/BRS.0b013e31819403ce

Plosker, G. L. (2014). Rivaroxaban: a review of its use in acute coronary syndromes. Drugs 74, 451-464. doi: 10.1007/s40265-014-0188-6

Pluchino, S., Quattrini, A., Brambilla, E., Gritti, A., Salani, G., Dina, G., et al. (2003). Injection of adult neurospheres induces recovery in a chronic model of multiple sclerosis. Nature 422, 688-694. doi: 10.1038/nature01552

Pluchino, S., Zanotti, L., Brini, E., Ferrari, S., and Martino, G. (2009). Regeneration and repair in multiple sclerosis: the role of cell transplantation. Neurosci. Lett. 456, 101-106. doi: 10.1016/j.neulet.2008.03.097

Prasad, K., Mohanty, S., Bhatia, R., Srivastava, M. V., Garg, A., Srivastava, A., et al. (2012). Autologous intravenous bone marrow mononuclear cell therapy for patients with subacute ischaemic stroke: a pilot study. Indian J. Med. Res. 136, 221-228. 
Ra, J. C., Shin, I. S., Kim, S. H., Kang, S. K., Kang, B. C., Lee, H. Y., et al. (2011). Safety of intravenous infusion of human adipose tissue-derived mesenchymal stem cells in animals and humans. Stem Cells Dev. 20, 1297-1308. doi: $10.1089 / \mathrm{scd} .2010 .0466$

Rabchevsky, A. G., Patel, S. P., and Springer, J. E. (2011). Pharmacological interventions for spinal cord injury: where do we stand? How might we step forward? Pharmacol. Ther. 132, 15-29. doi: 10.1016/j.pharmthera.2011.05.001

Rao, M. S., and Mattson, M. P. (2001). Stem cells and aging: expanding the possibilities. Mech. Ageing Dev. 122, 713-734. doi: 10.1016/S0047-6374(01)00224-X

Regal, L., Vanopdenbosch, L., Tilkin, P., Van Den Bosch, L., Thijs, V., Sciot, R., et al. (2006). The G93C mutation in superoxide dismutase 1: clinicopathologic phenotype and prognosis. Arch. Neurol. 63, 262-267. doi: 10.1001/archneur.63.2.262

Renton, A. E., Majounie, E., Waite, A., Simon-Sanchez, J., Rollinson, S., Gibbs, J. R., et al. (2011). A hexanucleotide repeat expansion in C9ORF72 is the cause of chromosome 9p21-linked ALS-FTD. Neuron 72, 257-268. doi: 10.1016/j.neuron.2011.09.010

Robberecht, W., and Philips, T. (2013). The changing scene of amyotrophic lateral sclerosis. Nat. Rev. Neurosci. 14, 248-264. doi: 10.1038/nrn3430

Rosado-De-Castro, P. H., Schmidt Fda, R., Battistella, V., Lopes De Souza, S. A., Gutfilen, B., Goldenberg, R. C., et al. (2013). Biodistribution of bone marrow mononuclear cells after intra-arterial or intravenous transplantation in subacute stroke patients. Regen. Med. 8, 145-155. doi: 10.2217/rme.13.2

Rosati, G. (2001). The prevalence of multiple sclerosis in the world: an update. Neurol. Sci. 22, 117-139. doi: 10.1007/s100720170011

Rosen, D. R., Siddique, T., Patterson, D., Figlewicz, D. A., Sapp, P., Hentati, A., et al. (1993). Mutations in $\mathrm{Cu} / \mathrm{Zn}$ superoxide dismutase gene are associated with familial amyotrophic lateral sclerosis. Nature 362, 59-62. doi: 10.1038/ 362059a0

Rowland, L. P., and Shneider, N. A. (2001). Amyotrophic lateral sclerosis. N. Engl. J. Med. 344, 1688-1700. doi: 10.1056/NEJM200105313442207

Rubio, D., Garcia-Castro, J., Martin, M. C., De La Fuente, R., Cigudosa, J. C., Lloyd, A. C., et al. (2005). Spontaneous human adult stem cell transformation. Cancer Res. 65, 3035-3039. doi: 10.1158/0008-5472.CAN-04-4194

Ruschenschmidt, C., Koch, P. G., Brustle, O., and Beck, H. (2005). Functional properties of ES cell-derived neurons engrafted into the hippocampus of adult normal and chronically epileptic rats. Epilepsia 46(Suppl. 5), 174-183. doi: 10.1111/j.1528-1167.2005.01028.x

Santos, J. M., Barcia, R. N., Simoes, S. I., Gaspar, M. M., Calado, S., Agua-Doce, A., et al. (2013). The role of human umbilical cord tissue-derived mesenchymal stromal cells $(\mathrm{UCX}(\mathrm{R}))$ in the treatment of inflammatory arthritis. J. Transl. Med. 11, 18. doi: 10.1186/1479-5876-11-18.

Savitz, S. I., Rosenbaum, D. M., Dinsmore, J. H., Wechsler, L. R., and Caplan, L. R. (2002). Cell transplantation for stroke. Ann. Neurol. 52, 266-275. doi: $10.1002 /$ ana. 60000

Scheff, S. W., Rabchevsky, A. G., Fugaccia, I., Main, J. A., and Lumpp, J. E. Jr. (2003). Experimental modeling of spinal cord injury: characterization of a forcedefined injury device. J. Neurotrauma 20, 179-193. doi: 10.1089/08977150360 547099

Schwid, S. R., and Panitch, H. S. (2007). Full results of the Evidence of Interferon Dose-Response-European North American Comparative Efficacy (EVIDENCE) study: a multicenter, randomized, assessor-blinded comparison of low-dose weekly versus high-dose, high-frequency interferon beta-1a for relapsing multiple sclerosis. Clin. Ther. 29, 2031-2048. doi: 10.1016/j.clinthera.2007. 09.025

Sheth, R. N., Manzano, G., Li, X., and Levi, A. D. (2008). Transplantation of human bone marrow-derived stromal cells into the contused spinal cord of nude rats. J. Neurosurg. Spine 8, 153-162. doi: 10.3171/SPI/2008/8/2/153

Shetty, P., Ravindran, G., Sarang, S., Thakur, A. M., Rao, H. S., and Viswanathan, C. (2009). Clinical grade mesenchymal stem cells transdifferentiated under xenofree conditions alleviates motor deficiencies in a rat model of Parkinson's disease. Cell Biol. Int. 33, 830-838. doi: 10.1016/j.cellbi.2009.05.002

Somoza, R., Juri, C., Baes, M., Wyneken, U., and Rubio, F. J. (2010). Intranigral transplantation of epigenetically induced BDNF-secreting human mesenchymal stem cells: implications for cell-based therapies in Parkinson's disease. Biol. Blood Marrow Transplant. 16, 1530-1540. doi: 10.1016/j.bbmt.2010.06.006

Sosa-Ortiz, A. L., Acosta-Castillo, I., and Prince, M. J. (2012). Epidemiology of dementias and Alzheimer's disease. Arch. Med. Res. 43, 600-608. doi: 10.1016/j.arcmed.2012.11.003
Sozio, P., Cerasa, L. S., Abbadessa, A., and Di Stefano, A. (2012). Designing prodrugs for the treatment of Parkinson's disease. Exp. Opin. Drug Discov. 7, 385-406. doi: 10.1517/17460441.2012.677025

Takagi, Y., Takahashi, J., Saiki, H., Morizane, A., Hayashi, T., Kishi, Y., et al. (2005). Dopaminergic neurons generated from monkey embryonic stem cells function in a Parkinson primate model. J. Clin. Invest. 115, 102-109. doi: $10.1172 /$ JCI21137

Takahashi, K., and Yamanaka, S. (2006). Induction of pluripotent stem cells from mouse embryonic and adult fibroblast cultures by defined factors. Cell 126, 663-676. doi: 10.1016/j.cell.2006.07.024

Tamura, A., Graham, D. I., McCulloch, J., and Teasdale, G. M. (1981). Focal cerebral ischaemia in the rat: 1 . Description of technique and early neuropathological consequences following middle cerebral artery occlusion. J. Cereb. Blood Flow Metab. 1, 53-60. doi: 10.1038/jcbfm. 1981.6

Thomson, J. A., Itskovitz-Eldor, J., Shapiro, S. S., Waknitz, M. A., Swiergiel, J. J., Marshall, V. S., et al. (1998). Embryonic stem cell lines derived from human blastocysts. Science 282, 1145-1147. doi: 10.1126/science.282.5391.1145

Tieu, K. (2011). A guide to neurotoxic animal models of Parkinson's disease. Cold Spring Harb. Perspect. Med. 1, a009316. doi: 10.1101/cshperspect.a009316

Uccelli, A., Milanese, M., Principato, M. C., Morando, S., Bonifacino, T., Vergani, L., et al. (2012). Intravenous mesenchymal stem cells improve survival and motor function in experimental amyotrophic lateral sclerosis. Mol. Med. 18, 794-804. doi: 10.2119/molmed.2011.00498

Van Blitterswijk, M., Dejesus-Hernandez, M., and Rademakers, R. (2012). How do C9ORF72 repeat expansions cause amyotrophic lateral sclerosis and frontotemporal dementia: can we learn from other noncoding repeat expansion disorders? Curr. Opin. Neurol. 25, 689-700. doi: 10.1097/WCO.0b013e32835a3efb

Van Damme, V., Govaerts, E., Nackaerts, K., Dooms, C., Wauters, I., and Vansteenkiste, J. (2013). Clinical factors predictive of long-term survival in advanced non-small cell lung cancer. Lung Cancer 79, 73-76. doi: 10.1016/j.lungcan.2012.09.015

van de Glind, E. M., van Enst, W. A., van Munster, B. C., Olde Rikkert, M. G., Scheltens, P., Scholten, R. J., et al. (2013). Pharmacological treatment of dementia: a scoping review of systematic reviews. Dement. Geriatr. Cogn. Disord. 36, 211-228. doi: 10.1159/000353892

Vance, C., Rogelj, B., Hortobagyi, T., De Vos, K. J., Nishimura, A. L., Sreedharan, J., et al. (2009). Mutations in FUS, an RNA processing protein, cause familial amyotrophic lateral sclerosis type 6. Science 323, 1208-1211. doi: 10.1126/science.1165942

Veelken, J. A., Laing, R. J., and Jakubowski, J. (1995). The Sheffield model of subarachnoid hemorrhage in rats. Stroke 26, 1279-1283. discussion: 1284. doi: 10.1161/01.STR.26.7.1279

Vescovi, A. L., Gritti, A., Galli, R., and Parati, E. A. (1999a). Isolation and intracerebral grafting of nontransformed multipotential embryonic human CNS stem cells. J. Neurotrauma 16, 689-693. doi: 10.1089/neu.1999.16.689

Vescovi, A. L., Parati, E. A., Gritti, A., Poulin, P., Ferrario, M., Wanke, E., et al. (1999b). Isolation and cloning of multipotential stem cells from the embryonic human CNS and establishment of transplantable human neural stem cell lines by epigenetic stimulation. Exp. Neurol. 156, 71-83. doi: 10.1006/exnr.1998. 6998

Von Euler, M., Seiger, A., and Sundstrom, E. (1997). Clip compression injury in the spinal cord: a correlative study of neurological and morphological alterations. Exp. Neurol. 145, 502-510. doi: 10.1006/exnr.1997.6481

Wegorzewska, I., Bell, S., Cairns, N. J., Miller, T. M., and Baloh, R. H. (2009). TDP-43 mutant transgenic mice develop features of ALS and frontotemporal lobar degeneration. Proc. Natl. Acad. Sci. U.S.A. 106, 18809-18814. doi: 10.1073/pnas.0908767106

Wei, G., Schubiger, G., Harder, F., and Muller, A. M. (2000). Stem cell plasticity in mammals and transdetermination in Drosophila: common themes? Stem Cells 18, 409-414. doi: 10.1634/stemcells.18-6-409

Wei, L., Cui, L., Snider, B. J., Rivkin, M., Yu, S. S., Lee, C. S., et al. (2005). Transplantation of embryonic stem cells overexpressing Bcl-2 promotes functional recovery after transient cerebral ischemia. Neurobiol. Dis. 19, 183-193. doi: 10.1016/j.nbd.2004.12.016

Weiss, S., Reynolds, B. A., Vescovi, A. L., Morshead, C., Craig, C. G., and van der Kooy, D. (1996). Is there a neural stem cell in the mammalian forebrain? Trends Neurosci. 19, 387-393. doi: 10.1016/S0166-2236(96)10035-7

Wernig, M., Zhao, J. P., Pruszak, J., Hedlund, E., Fu, D., Soldner, F., et al. (2008). Neurons derived from reprogrammed fibroblasts functionally integrate 
into the fetal brain and improve symptoms of rats with Parkinson's disease. Proc. Natl. Acad. Sci. U.S.A. 105, 5856-5861. doi: 10.1073/pnas.08016 77105

Willner, P. (1984). The validity of animal models of depression. Psychopharmacology (Berl.) 83, 1-16.

Xu, L., Shen, P., Hazel, T., Johe, K., and Koliatsos, V. E. (2011). Dual transplantation of human neural stem cells into cervical and lumbar cord ameliorates motor neuron disease in SOD1 transgenic rats. Neurosci. Lett. 494, 222-226. doi: 10.1016/j.neulet.2011.03.017

Yu, J., Vodyanik, M. A., Smuga-Otto, K., Antosiewicz-Bourget, J., Frane, J. L., Tian, S., et al. (2007). Induced pluripotent stem cell lines derived from human somatic cells. Science 318, 1917-1920. doi: 10.1126/science.1151526

Zhu, S. F., Zhong, Z. N., Fu, X. F., Peng, D. X., Lu, G. H., Li, W. H., et al. (2013). Comparison of cell proliferation, apoptosis, cellular morphology and ultrastructure between human umbilical cord and placenta-derived mesenchymal stem cells. Neurosci. Lett. 541, 77-82. doi: 10.1016/j.neulet.2013. 03.018

Zurita, M., and Vaquero, J. (2006). Bone marrow stromal cells can achieve cure of chronic paraplegic rats: functional and morphological outcome one year after transplantation. Neurosci. Lett. 402, 51-56. doi: 10.1016/j.neulet.2006. 03.069

Conflict of Interest Statement: The authors declare that the research was conducted in the absence of any commercial or financial relationships that could be construed as a potential conflict of interest.

Received: 24 January 2014; accepted: 22 April 2014; published online: 14 May 2014. Citation: Adami R, Scesa G and Bottai D (2014) Stem cell transplantation in neurological diseases: improving effectiveness in animal models. Front. Cell Dev. Biol. 2:17. doi: $10.3389 /$ fcell.2014.00017

This article was submitted to Stem Cell Treatments, a section of the journal Frontiers in Cell and Developmental Biology.

Copyright (C) 2014 Adami, Scesa and Bottai. This is an open-access article distributed under the terms of the Creative Commons Attribution License (CC BY). The use, distribution or reproduction in other forums is permitted, provided the original author(s) or licensor are credited and that the original publication in this journal is cited, in accordance with accepted academic practice. No use, distribution or reproduction is permitted which does not comply with these terms. 